\title{
Synthesis of miktoarm star copolymer Ru(II) complexes by click-to-chelate approach
}

\author{
Nao Xiao ${ }^{1}$, Yougen Chen ${ }^{1}$, Xiande Shen ${ }^{2}$, Chunhong Zhang ${ }^{2}$, Shigenobu Yano ${ }^{3}$, Michael Gottschaldt ${ }^{4}$, \\ Ulrich S Schubert ${ }^{4}$, Toyoji Kakuchi ${ }^{1}$ and Toshifumi Satoh ${ }^{1}$
}

A series of $A B_{2^{-}}, A B C-,(A B)_{2^{-}}, A_{2} B_{2^{-}}$and $A B C D$-type miktoarm copolymer $R u(I I)$ complexes was synthesized by a stepwise chelating method, which involved the first-step chelating reaction of $\mathrm{Ru}(\mathrm{II})(\mathrm{DMSO})_{4} \mathrm{Cl}_{2}$ with a polymer-substituted $2-(1 \mathrm{H}-1,2,3-$ triazol-4-yl)pyridine (tapy) or 2,6-bis(1H-1,2,3-triazol-4-yl)pyridine (bitapy) ligand to produce a stable polymer Ru(II) monocomplex, and a second-step chelating reaction of the polymer $\mathrm{Ru}(\mathrm{II})$ mono-complex with another tapy or bitapy ligand to afford the miktoarm copolymer Ru(II) complexes. In order to synthesize them, the polymer-substituted tapy and bitapy ligands were first prepared by the click reaction of azido-terminated polymers with 2-ethynylpyridine and 2,6-diethynylpyridine, respectively. The azido-terminated polystyrene (PS) and poly( $n$-butyl acrylate) (PBA) were prepared by the atom-transfer radical polymerizations of styrene and $n$-butyl acrylate using ethyl 2-bromoisobutyrate as the initiator, followed by the substitutions of their end bromines with an azido group, respectively. The azido-terminated poly( $n$-hexyl isocyanate) was prepared by the living coordination polymerization of $n$-hexyl isocyanate using dichloro(cyclopentadienyl)(6-azidohexyloxy)titanium that was prepared by mixing 6 -azido-1-hexanol with trichloro(cyclopentadienyl)titanium before the polymerization. The azido-terminated poly(styrene oxide) and poly( $\varepsilon$-caprolactone) were synthesized by the controlled/living ring-opening polymerizations of $\varepsilon$ caprolactone using diphenyl phosphate as the catalyst and of styrene oxide using the phosphazene base of $t-\mathrm{Bu}_{-} \mathrm{P}_{4}$ as the catalyst, respectively, in which 6-azido-1-hexanol was used as the initiator.

Polymer Journal (2013) 45, 216-225; doi:10.1038/pj.2012.100; published online 13 June 2012

Keywords: click chemistry; miktoarm star copolymer; Ru(II) complexes; stepwise chelating

\section{INTRODUCTION}

In general, supramolecular chemistry involves diverse non-covalent interactions, such as hydrogen bonding, metal/ligand coordination and hydrophobic interactions, which therefore involve new fields including self-assembly, molecular recognition and topological chemistry. Among the non-covalent interactions, the chelating properties of transition metal cations toward the appropriate ligands undoubtedly has a significant role in supramolecular chemistry. Transition metal cations, such as $\mathrm{Cu}(\mathrm{II}), \mathrm{Co}(\mathrm{II}), \mathrm{Ni}(\mathrm{II}), \mathrm{Fe}(\mathrm{II}), \mathrm{Zn}(\mathrm{II})$ and $\mathrm{Ru}(\mathrm{II})$, are usually employed, and bi- and tridentate amines are extensively utilized as the chelating ligands due to their strong coordinating abilities. Many efforts have already been devoted to design and for the constitution of various macromolecular architectures based on the metal/ligand non-covalent interaction. In particular, the complexes of $\mathrm{Ru}(\mathrm{II})$ with bipyridyl and terpyridyl ligands are typically utilized because of their easy formation and highly stable properties. For instance, Fraser et al. ${ }^{1-4}$ reported the synthesis of $\mathrm{Ru}(\mathrm{II})$ supramolecular polymers by the coordination reaction between
$\mathrm{Ru}(\mathrm{II})$ and bipyridyl derivatives, including star-shaped macromolecular architectures with an arm number varying from three to six by either divergent or convergent methods. In addition, Rehahn et al..$^{5}$ initially started the field of $\mathrm{Ru}$ (II) supramolecular complexes based on terpyridyl chelating ligands leading to linear polymers. Schubert et al. ${ }^{6}$ then expanded the terpyridyl chelating method to prepare three- and four-armed star-shaped $\mathrm{Ru}(\mathrm{II})$ supramolecular polymers. The facile and convenient chelating method has become one of the important issues for constructing well-defined macromolecular architectures by forming the non-covalent $\mathrm{Ru}(\mathrm{II})$ complex.

Besides the molecular design of the macromolecular $\mathrm{Ru}(\mathrm{II})$ complex using the bipyridyl and terpyridyl compounds, the coppercatalyzed click reaction of azides with alkynes containing amino groups, such as 2-ethynylprydine and 2,6-diethynylpyridine, has been recently developed as one of the promising methods for preparing biand tridentate amine ligands consisting of the $1 \mathrm{H}$-1,2,3-triazole group due to its synthetic simplicity. ${ }^{7-12}$ The application of such bi- and

${ }^{1}$ Division of Biotechnology and Macromolecular Chemistry, Graduate School of Engineering, Hokkaido University, Sapporo, Japan; ${ }^{2}$ College of Materials Science and Chemical Engineering, Harbin Engineering University, Harbin, China; ${ }^{3}$ Graduate School of Materials Science, Nara Institute of Science and Technology, Nara, Japan and ${ }^{4}$ Laboratory for Organic and Macromolecular Chemistry, Friedrich-Schiller-University Jena, Jena, Germany

Correspondence: Professor T Kakuchi or Associate Professor T Satoh, Division of Biotechnology and Macromolecular Chemistry, Graduate School of Engineering, Hokkaido University, N13W8, Kita-ku, Sapporo 060-8628, Japan.

E-mail: kakuchi@poly-bm.eng.hokudai.ac.jp or satoh@poly-bm.eng.hokudai.ac.jp

Received 6 April 2012; accepted 27 April 2012; published online 13 June 2012 
tridentate amines as chelating ligands is of great potential and significantly expected in synthetic polymer chemistry. ${ }^{13-14}$ In particular, the combination of the click reaction and controlled/ living polymerization techniques, such as the atom-transfer radical polymerization and living ring-opening polymerization, provides versatile procedures to produce well-defined polymeric chelating ligands possessing the $1 H-1,2,3$-triazole-containing bi- and tridentate amine groups. For example, we successfully prepared three- and four-armed star-branched PSs with a $\mathrm{Ru}(\mathrm{II})$ complex core by the click-to-chelate approach; ${ }^{15}$ that is, (i) the synthesis of the bromine-terminated PS (PS-Br) by atom-transfer radical polymerization, (ii) the conversion of PS-Br into the endfunctionalized PS with the azido group $\left(\mathrm{PS}-\mathrm{N}_{3}\right)$, (iii) the click reaction between $\mathrm{PS}_{-} \mathrm{N}_{3}$ with 2-ethynylprydine and 2,6dietynylpyridine to afford a 2-(1-PS- $1 H$-1,2,3-triazol-4-yl)pyridine (PS-tapy) and a 2,6-bis(1-PS-1H-1,2,3-triazol-4-yl)pyridine ( $\mathrm{PS}_{2}$ bitapy), respectively, and (iv) the one-pot synthesis of star-shaped PSs through the formation of $\mathrm{Ru}(\mathrm{II})$ complexes with PS-tapy and $\mathrm{PS}_{2}$-bitapy ligands, during which the reduction reaction of the commercial $\mathrm{Ru}(\mathrm{III}) \mathrm{Cl}_{3}$ was applied. Notably, the direct utilization of $\mathrm{Ru}(\mathrm{III}) \mathrm{Cl}_{3}$ involved the formation of an intermediate of the $\mathrm{Ru}(\mathrm{III}) \mathrm{Cl}_{3}$ mono-complex that was sensitive to external environments and reactive groups, such as the ethynyl group, causing difficulty in isolating and handling such a $\mathrm{Ru}(\mathrm{III}) \mathrm{Cl}_{3}$ monocomplex. The $\mathrm{Ru}(\mathrm{II})$ complex finally formed by the reaction of the $\mathrm{Ru}(\mathrm{III}) \mathrm{Cl}_{3}$ mono-complex with ligands under a reducing environment. Thus, a reducing agent, such as $N$-ethylmorpholine, and some reductive solvents, such as $\mathrm{N}, \mathrm{N}$-dimethylformamide and ethanol, are required for the conversion of $\mathrm{Ru}$ (III) to $\mathrm{Ru}(\mathrm{II}){ }^{16-17}$ Although this one-pot method is very suitable and efficient for preparing star-shaped homopolymers consisting of the same polymeric ligands, it is hardly applicable for synthesizing miktoarm star copolymers. In order to explore the scope of the click-to-chelate method, we now focus on the convenient synthesis of miktoarm star copolymers based on a stepwise chelating method. Specifically, a $\mathrm{Ru}(\mathrm{II})(\mathrm{DMSO})_{4} \mathrm{Cl}_{2}$ precursor is used and offers the possibility to synthesize a very stable $\mathrm{Ru}(\mathrm{II})$ mono-complex without any reducing steps, and particularly, the $\mathrm{Ru}(\mathrm{II})$ mono-complex can be readily isolated under ordinary conditions. ${ }^{18-19}$ Thus, after the first polymer possessing a bi- or tridentate amine ligand is reacted with $\mathrm{Ru}$ (II) to produce a stable $\mathrm{Ru}$ (II) mono-complex, the $\mathrm{Ru}(\mathrm{II})$ mono-complex is isolated and further chelated with the second polymeric ligand possessing a bi- or tridentate amino group to produce a star-shaped polymer $\mathrm{Ru}(\mathrm{II})$ complex. A star-shaped homopolymer is synthesized when the first and second polymers are the same, and a miktoarm star-shaped copolymer when they are different. In this article, we used PS, PBA, poly $(n$-hexyl isocyanate) (PHIC), poly(e-caprolactone) (PCL) and poly(styrene oxide) (PSO) as the arm polymers for the synthesis of star copolymer $\mathrm{Ru}(\mathrm{II})$ complexes, that is, with three-miktoarm: (Ru(PS-tapy)(PHIC-tapy $\left.)_{2}\right)$ $\left(\mathrm{SbF}_{6}\right)_{2},\left(\mathrm{Ru}(\mathrm{PS} \text {-tapy })_{2}(\mathrm{PHIC}-\mathrm{tapy})\right)\left(\mathrm{SbF}_{6}\right)_{2},\left(\mathrm{Ru}\left(\mathrm{PS}_{2}\right.\right.$-bitapy) (PSO-tapy) $(\mathrm{DMSO}))\left(\mathrm{SbF}_{6}\right)_{2},(\mathrm{Ru}(\mathrm{PS}-$ bitapy-PBA $\left.)(\mathrm{PSO}-\mathrm{tapy})(\mathrm{DMSO}))\left(\mathrm{SbF}_{6}\right)_{2}\right)$ and ( $\mathrm{Ru}$ (PS-bitapy- PBA)(PCL-tapy)(DMSO) $\left(\mathrm{SbF}_{6}\right)_{2}$, and with fourmiktoarm: ( $\mathrm{Ru}\left(\mathrm{PS}_{2}\right.$-bitapy) $\left(\mathrm{PHIC}_{2}\right.$-bitapy) $)\left(\mathrm{SbF}_{6}\right)_{2}, \quad(\mathrm{Ru}$ (PS-bitapy$\left.\mathrm{PBA})_{2}\right)\left(\mathrm{SbF}_{6}\right)_{2}$ and $\left(\mathrm{Ru}\left(\mathrm{PS}-\right.\right.$ bitapy-PBA) $(\mathrm{PSO}-$ bitapy-PCL) $\left.)\left(\mathrm{SbF}_{6}\right)_{2}\right)$, as shown in Scheme 1.

\section{EXPERIMENTAL PROCEDURE}

\section{Materials}

Toluene (>99.5\%; water content, <0.001\%) was purchased from Kanto Chemical Co, Inc. (Sapporo, Japan) and distilled over sodium benzophenone ketyl before use. Styrene oxide (SO; $>98.0 \%$, Tokyo Chemical Industry Co, Ltd. (Sapporo, Japan) (TCI)) was distilled over $\mathrm{NaH}$ before use. Dry dichloromethane $\left(\mathrm{CH}_{2} \mathrm{Cl}_{2} ;>99.5 \%\right)$, N,N-dimethylformamide (>99.5\%), styrene $(>99.0 \%$ ), $n$-butyl acrylate (BA; $>99.0 \%), n$-hexyl isocyanate (HIC; $>98.0 \%$ ), $\varepsilon$-caprolactone ( $\varepsilon$-CL; $>99 \%$ ), ethyl 2-bromoisobutyrate ( $>98.0 \%$ ) and $N, N, N^{\prime}, N^{\prime \prime}, N^{\prime \prime}$-pentamethyldiethylenetriamine (PMDETA; > 99.0\%) from TCI, and were used after distillation from $\mathrm{CaH}_{2}$ in vacuo. Copper bromide (Cu(I)Br; 99.999\%), anisole (99.7\%) 1-tert-butyl-4,4,4-tris(dimethylamino)2,2-bis(tris(dimethylamino)phosphoranylidenamino)- $2 \Lambda^{\mathrm{s}}, 4 \Lambda^{\mathrm{s}}$-catenadi(phosphazene) ( $t$-Bu- $\mathrm{P}_{4}, 1.0 \mathrm{M}$ solution in $n$-hexane), 2-ethynylpyridine (98\%), and silver hexafluoroantimonate $\left(\mathrm{AgSbF}_{6} ; 98 \%\right)$ were purchased from the SigmaAldrich Chemicals Co.; sodium azide $(>97.0 \%)$, acetic anhydride $(>97.0 \%)$, benzoic acid (>99.5\%), 2-propanol (>99.7\%), diphenyl phosphate (>99\%) and boron trifluoride diethyl etherate $\left(\mathrm{BF}_{3} \cdot \mathrm{OEt}_{2} ; 95.0 \%\right)$ from Kanto Chemical Co., Inc. (Ichikawa, Japan); trichloro(cyclopentadienyl)titanium $\left(\mathrm{CpTiCl}_{3}\right.$; $>98.0 \%$ ) and acetone (>99.5\%, TCI) from TCI; and Amberlyst ${ }^{\circledR}$ A21 from Acros Organics (Tokyo, Japan) and they were used as received. 6-Azido-1hexanol, ${ }^{20}$ 2,6-diethynylpyridine, ${ }^{21}$ and $\mathrm{Ru}(\mathrm{II})(\mathrm{DMSO})_{4} \mathrm{Cl}_{2}{ }^{18}$ were prepared according to methods in the literatures.

\section{Instruments}

The ${ }^{1} \mathrm{H}$ and ${ }^{13} \mathrm{C}$ NMR spectra were recorded using a JEOL JNM-A400II instrument (JEOL, Tachikawa, Japan) in $\mathrm{CDCl}_{3}$ as the solvent. The infrared (IR) spectra were recorded using a Perkin-Elmer Paragon 1000 FTIR instrument (Perkin-Elmer, Yokohama, Japan). The ultraviolet-visible spectra were recorded using a Jasco V-550 spectrophotometer (Jaso, Tokyo, Japan). The synthesis of azido-terminated poly(SO) $\left(\mathrm{PSO}-\mathrm{N}_{3}\right)$ and the azido-terminated PCL $\left(\mathrm{PCL}-\mathrm{N}_{3}\right)$ were carried out in an MBRAUN stainless steel glovebox (MBRAUN, Wako, Japan) equipped with a gas purification system (molecular sieves and copper catalyst) under a dry argon atmosphere $\left(\mathrm{H}_{2} \mathrm{O}, \mathrm{O}_{2}<1\right.$ p.p.m.). The moisture and oxygen contents in the glovebox were monitored by an MB-MO-SE 1 and MBOX-SE 1, respectively. Preparative SEC was performed using a JAI LC-9201 HPLC system equipped with a JAI RI-50s refractive index detector and a JAI JAIGEL-3H column $\left(20 \mathrm{~mm} \times 600 \mathrm{~mm}\right.$; exclusion limit, $\left.7 \times 10^{4}\right)$ using tetrahydrofuran (THF) or $\mathrm{CHCl}_{3}$. The SEC measurements in THF were performed using a Jasco GPC-900 system equipped with a Waters Ultrastyragel column (linear; $7.8 \mathrm{~mm} \times 300 \mathrm{~mm}$; exclusion limit, $1 \times 10^{7}$ ) and two Shodex KF-804L columns (linear; $8 \mathrm{~mm} \times 300 \mathrm{~mm}$; exclusion limit, $4 \times 10^{5}$ ) at the flow rate of $1.0 \mathrm{ml} \mathrm{min}{ }^{-1}$ and $40^{\circ} \mathrm{C}$. The SEC measurements in $\mathrm{CHCl}_{3}$ were performed using a Jasco GPC-900 system equipped with two Shodex K-805L columns (linear; $8 \mathrm{~mm} \times 300 \mathrm{~mm}$; exclusion limit, $4 \times 10^{6}$ ) with the flow rate of $0.8 \mathrm{ml} \mathrm{min}^{-1}$ and $40^{\circ} \mathrm{C}$. The number-average molecular weight $\left(M_{\mathrm{n}(\mathrm{SEC})}\right)$ and polydispersity $\left(M_{\mathrm{w}} / M_{\mathrm{n}}\right)$ of the polymers were calculated on the basis of a PS calibration. Matrix-assisted laser desorption ionization time-of-flight mass spectrometry (MALDI-TOF MS) of the obtained polymers was performed using an Applied Biosystems Voyager-DE STR-H (Applied Biosystems, Scottsdale, AZ, USA) equipped with a $337-\mathrm{nm}$ nitrogen laser ( $3 \mathrm{~nm}$ pulse width). Two hundred shots were accumulated for the spectra at a $25 \mathrm{kV}$ acceleration voltage in the reflector mode and calibrated using the PS standard with a linear calibration. For the MADLI-TOF MS measurement, the polymer $\left(10 \mathrm{mg} \mathrm{ml}^{-1}\right)$ in THF, a matrix (Dithranol, $20 \mathrm{mg} \mathrm{ml}^{-1}$ ) in THF and a cationizing agent (sodium trifluoroacetate, $10 \mathrm{mg} \mathrm{ml}^{-1}$ ) in methanol were mixed in the ratio of the polymer/matrix/cationizing agent of $5 \mu \mathrm{l} / 25 \mu \mathrm{l} / 5 \mu \mathrm{l}$, and $1 \mu \mathrm{l}$ of the mixed solution was deposited on the sample holder.

\section{Synthesis of azido-terminated PHIC (PHIC-N ${ }_{3}$ )}

To a 50-ml Schlenk flask, the trichloro(cyclopentadienyl)titanium (CpTiCl3) $(345.0 \mathrm{mg}, 1.6 \mathrm{mmol})$ and dry dichloromethane $(5.0 \mathrm{ml})$ were added, and then stirred to homogeneity. A dichloromethane stock solution of 6-azido-1-hexanol $(1.2 \mathrm{ml}, 1.6 \mathrm{mmol})$ was then introduced. After the reaction was carried out at room temperature for $3 \mathrm{~h}$, the solvent was removed under vacuum. $n$-Hexyl isocyanate (HIC; $5.8 \mathrm{ml}, 40.0 \mathrm{mmol}$ ) was added and the flask was sealed off. The polymerization was carried out for $24 \mathrm{~h}$ at $0{ }^{\circ} \mathrm{C}$ to afford a PHIC living chain as a solid product. Termination was achieved by the addition of an excess amount of acetic anhydride $(22.3 \mathrm{ml}, 238.0 \mathrm{mmol})$ and BF3 $\cdot$ OEt2 $(2.9 \mathrm{ml}, 23.5 \mathrm{mmol})$. The crude product was purified by the reprecipitation from THF to methanol to give PHIC$\mathrm{N}_{3}$ as a white solid (3.7 g, 73.0\%). $M_{\mathrm{n}(\mathrm{NMR})}, 5300 ; M_{\mathrm{n}(\mathrm{SEC})}, 3900 ; M_{\mathrm{w}} / M_{\mathrm{n}}, 1.09$. 


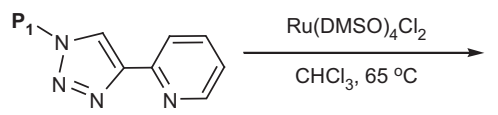

PS-tapy

( $\left.P_{1}=P S\right)$

PHIC-tapy

( $P_{1}=$ PHIC)<smiles></smiles>

$\mathrm{Ru}$ (PS-tapy)(DMSO) ${ }_{2} \mathrm{Cl}_{2}$ ( $P_{1}=$ PS)

$\mathrm{Ru}$ (PHIC-tapy)(DMSO) ${ }_{2} \mathrm{Cl}_{2}$ $\left(\mathrm{P}_{1}=\mathrm{PHIC}\right)$
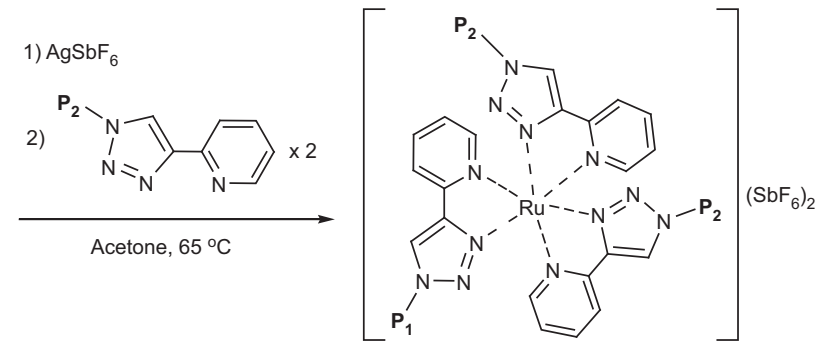

[Ru(PS-tapy) $\left.)_{3}\right]\left(\mathrm{SbF}_{6}\right)_{2}$

$\left(P_{1}, P_{2}=P S\right)$

$\left[\mathrm{Ru}(\mathrm{PS} \text {-tapy)(PHIC-tapy })_{2}\right]\left(\mathrm{SbF}_{6}\right)_{2}$
$\left(\mathrm{P}_{1}=\mathrm{PS}, \mathrm{P}_{2}=\mathrm{PHIC}\right)$ $\left[R u(P S-t a p y)_{2}\left(P_{H}\right.\right.$ IC-tapy $\left.)\right]\left(\text { SbF }_{6}\right)_{2}$
$\left(P_{1}=\right.$ PHIC, $P_{2}=$ PS $)$

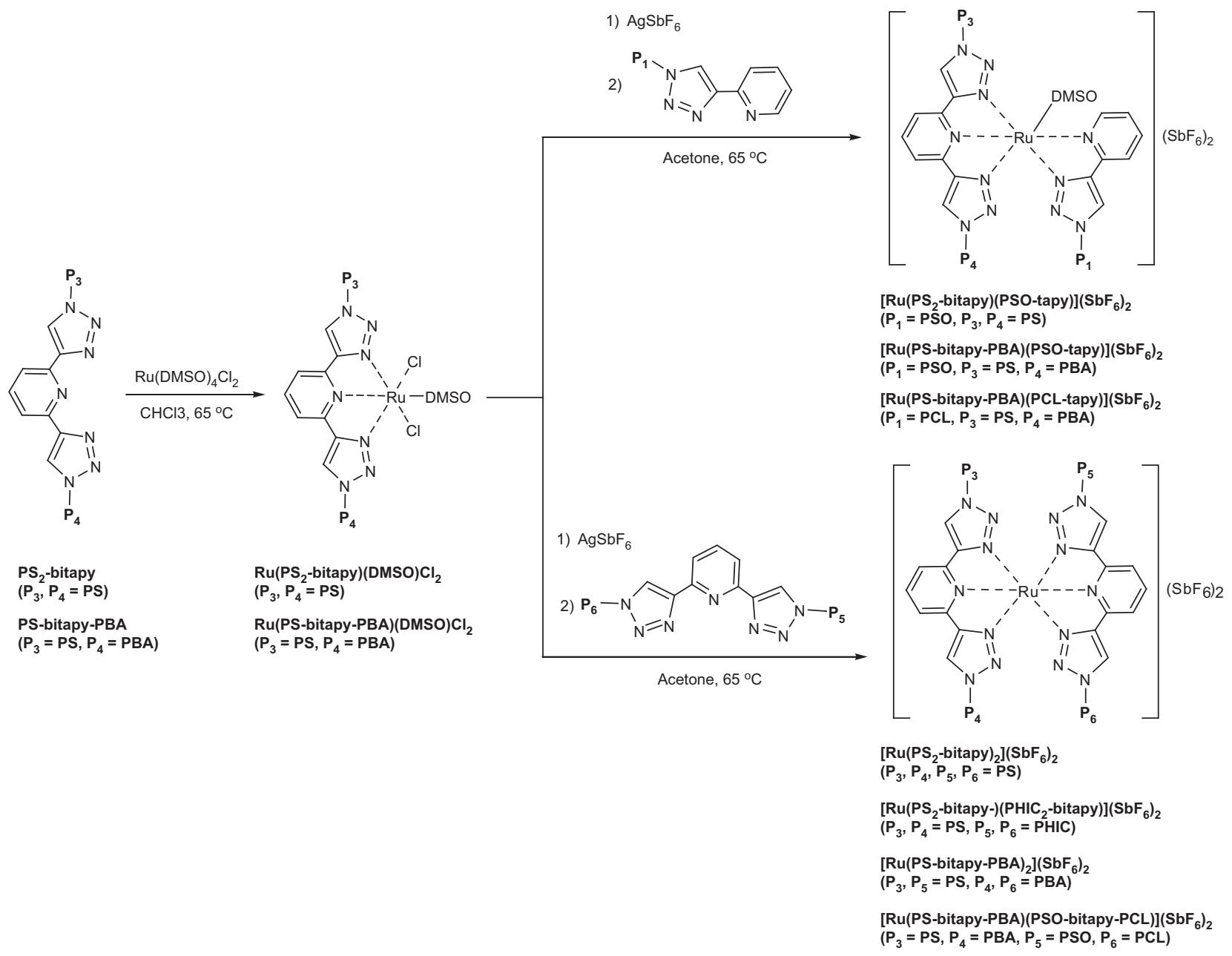

Scheme 1 Synthesis of star-shaped polymer Ru(II) complexes with three and four miktoarms consisting of polystyrene (PS), poly( $n$-butyl acrylate) (PBA), poly(n-hexyl isocyanate) (PHIC), poly( $\varepsilon$-caprolactone) (PCL) or poly(styrene oxide) (PSO).

Preparation of 2-(1-PHIC-1H-1,2,3-triazol-4-yl)pyridine (PHIC-tapy) Method A: $\mathrm{Cu}(\mathrm{I}) \mathrm{Br}(43.0 \mathrm{mg}, 0.3 \mathrm{mmol})$ was added to a single-neck 100-ml flask capped with a rubber plug in a glovebox. PHIC- $\mathrm{N}_{3}\left(M_{\mathrm{n}(\mathrm{SEC})}, 3900 ; 1.17 \mathrm{~g}\right.$, $0.3 \mathrm{mmol})$, 2-ethynylpyridine $(60.6 \mu \mathrm{l}, 0.6 \mathrm{mmol})$, PMDETA $(62.6 \mathrm{ml}, 0.3 \mathrm{mmol})$ and THF $(10.0 \mathrm{ml})$ were added to another flask. The mixture was degassed by bubbling with argon gas for $20 \mathrm{~min}$ and then transferred to the 100-ml flask. After the reaction mixture was stirred at room temperature for $48 \mathrm{~h}$, it was diluted with THF, and then passed through a short $\mathrm{SiO}_{2}$ column to remove the copper complex. The solvent was removed under reduced pressure. The crude polymer was purified by dialysis in methanol and dried in vacuo to give PHIC-tapy as a white solid (1.13 g, 92.0\%). $M_{\mathrm{n}(\mathrm{NMR})}, 5000 ; M_{\mathrm{n}(\mathrm{SEC})}, 4000 ; M_{\mathrm{w}} / M_{\mathrm{n}}, 1.09$.

\section{Preparation of 2,6-bis(1-PHIC-1H-1,2,3-triazol-4-yl)pyridine} (PHIC 2 -bitapy)

Method B: $\mathrm{Cu}(\mathrm{I}) \mathrm{Br}(86.1 \mathrm{mg}, 0.6 \mathrm{mmol})$ was added to a single-neck $100-\mathrm{ml}$ flask capped with a rubber plug in a glovebox. PHIC- $\mathrm{N}_{3}\left(M_{\mathrm{n} \text { (SEC) }}, 3900 ; 2.34 \mathrm{~g}\right.$, 
$0.6 \mathrm{mmol}$ ), 2,6-diethynylpyridine ( $38.1 \mathrm{mg}, 0.3 \mathrm{mmol})$, PMDETA ( $125.3 \mu \mathrm{l}$, $0.6 \mathrm{mmol})$ and THF $(20.0 \mathrm{ml})$ were added to a flask, the mixture was degassed by bubbling with argon gas for $20 \mathrm{~min}$ and then transferred to a 100-ml flask. After stirring at room temperature for $48 \mathrm{~h}$, the reaction mixture was diluted with THF, then the solution was passed through a short $\mathrm{SiO}_{2}$ column to remove the copper complex. After the solvent was removed under reduced pressure, the resulting residue was purified by preparative SEC using THF as the eluent and dried in vacuo to give $\mathrm{PHIC}_{2}$-bitapy as a white solid $(1.64 \mathrm{~g}$, $69.0 \%) . M_{\mathrm{n}(\mathrm{NMR})}, 10200 ; M_{\mathrm{n}(\mathrm{SEC})}, 9900 ; M_{\mathrm{w}} / M_{\mathrm{n}}, 1.05$.

\section{Preparation of 2-ethynyl-6-(1-PS ${ }^{\mathrm{II}}-1 H$-1,2,3-triazol-4-yl)pyridine (PS II-etapy)}

Method A was used with $\mathrm{Cu}(\mathrm{I}) \mathrm{Br}(7.2 \mathrm{mg}, 50.0 \mathrm{mmol}), \mathrm{PS}^{\mathrm{II}}-\mathrm{N}_{3}\left(M_{\mathrm{n}(\mathrm{SEC})}, 4700\right.$; $235.0 \mathrm{mg}, 50 \mu \mathrm{mol}), 2,6$-diethynylpyridine $(12.7 \mathrm{mg}, 0.1 \mathrm{mmol})$, PMDETA $(10.45 \mu \mathrm{l}, 50 \mu \mathrm{mol})$ and THF $(5.0 \mathrm{ml})$. The crude product was purified by dialysis in methanol and dried to yield $\mathrm{PS}^{\mathrm{II}}$-etapy as a light yellow solid $(222.9 \mathrm{~g}, 92.5 \%) . M_{\mathrm{n}(\mathrm{NMR})}, 5000 ; M_{\mathrm{n}(\mathrm{SEC})}, 4400 ; M_{\mathrm{w}} / M_{\mathrm{n}}, 1.26$.

Preparation of 2-(1-PS ${ }^{\mathrm{II}}-1 \mathrm{H}-1,2,3-$ triazol-4-yl)-6-(1-PBA-1H-1,2,3triazol-4-yl)pyridine (PS ${ }^{\mathrm{II}}$-bitapy-PBA)

Method C: $\mathrm{Cu}(\mathrm{I}) \mathrm{Br}(14.3 \mathrm{mg}, 0.1 \mathrm{mmol})$ was added to a single-neck $100-\mathrm{ml}$ flask capped with a rubber plug in a glovebox. PS ${ }^{\mathrm{II}}$-etapy $\left(M_{\mathrm{n}(\mathrm{SEC})}, 4400\right.$; $440.0 \mathrm{mg}, 0.1 \mathrm{mmol})$, PBA- $\mathrm{N}_{3}\left(M_{\mathrm{n}(\mathrm{SEC})}, 4700 ; 470.0 \mathrm{mg}, 0.1 \mathrm{mmol}\right)$, PMDETA $(20.9 \mu \mathrm{l}, 0.1 \mathrm{mmol})$ and THF $(10.0 \mathrm{ml})$ were added to another flask. The mixture was degassed by bubbling with argon gas for $20 \mathrm{~min}$ and then transferred to the $100-\mathrm{ml}$ flask. After stirring at room temperature for $48 \mathrm{~h}$, the reaction mixture was diluted with THF and passed through a short $\mathrm{SiO}_{2}$ column to remove the copper complex. The residue was purified by preparative SEC using $\mathrm{CHCl}_{3}$ as the eluent followed by dialysis in methanol to obtain PS ${ }^{I I}$-bitapy-PBA as a light yellow solid $(696.2 \mathrm{mg}, 76.5 \%) . M_{\mathrm{n}(\mathrm{SEC})}$, $11300 ; M_{\mathrm{w}} / M_{\mathrm{n}}, 1.15$.

Preparation of 2-(1-poly(SO)-1H-1,2,3-triazol-4-yl)-6-(1-PCL ${ }^{\mathrm{I}}-1 \mathrm{H}-$ 1,2,3-triazol-4-yl)pyridine (PSO-bitapy-PCLI)

Method $\mathrm{C}$ was used with $\mathrm{Cu}(\mathrm{I}) \mathrm{Br}(6.5 \mathrm{mg}, 45.5 \mu \mathrm{mol})$, PSO-etapy $\left(M_{\mathrm{n}(\mathrm{SEC})}\right.$, $4600 ; 215.0 \mathrm{mg}, 46.7 \mu \mathrm{mol}), \mathrm{PCL}^{\mathrm{I}}-\mathrm{N}_{3}\left(M_{\mathrm{n}(\mathrm{NMR})}, 5500 ; 250.3 \mathrm{mg}, 45.5 \mu \mathrm{mol}\right)$, PMDETA $(9.5 \mu \mathrm{l}, 45.5 \mu \mathrm{mol})$ and THF $(10 \mathrm{ml})$ to yield PSO-bitapy-PCL ${ }^{\mathrm{I}}$ as a light yellow solid (369.4 mg, 79.4\%). $M_{\mathrm{n}(\mathrm{SEC})}, 14600 ; M_{\mathrm{w}} / M_{\mathrm{n}}, 1.18$.

\section{Preparation of $\mathrm{Ru}\left(\mathrm{PS}^{\mathrm{II}}\right.$-bitapy-PBA)(DMSO) $\mathrm{Cl}_{2}$}

Method D: To a 10-ml needle flask containing $\mathrm{CHCl}_{3}(1.0 \mathrm{ml}), \mathrm{Ru}(\mathrm{DMSO})_{4} \mathrm{Cl}_{2}$ $(5.8 \mathrm{mg}, 12.0 \mu \mathrm{mol})$ and PSII-bitapy-PBA $\left(M_{\mathrm{n}(\mathrm{SEC})}, 11300 ; 113.0 \mathrm{mg}\right.$, $10.0 \mu \mathrm{mol})$ were added. The mixture was degassed by three freeze-pump-thaw cycles. The yellow-green mixture was then heated at $65^{\circ} \mathrm{C}$ for $24 \mathrm{~h}$. After cooling to room temperature, the solvent was removed. The crude product was further purified by preparative size exclusion chromatography using $\mathrm{CHCl}_{3}$ as the eluent, followed by dialysis in methanol to yield $\mathrm{Ru}$ (PS ${ }^{\mathrm{II}}$-bitapy-PBA) (DMSO) $\mathrm{Cl}_{2}$ as an orange-red solid $(98.0 \mathrm{mg}, 84.8 \%) . M_{\mathrm{n}(\mathrm{SEC})}, 11400 ; M_{\mathrm{W}} / M_{\mathrm{n}}$, 1.25

\section{Preparation of (Ru(PS ${ }^{\mathrm{II}}$-bitapy-PBA)(PSO-tapy) $\left.(\mathrm{DMSO})\right)\left(\mathrm{SbF}_{6}\right)_{2}$} Method E: A mixture of $\mathrm{Ru}\left(\mathrm{PS}^{\mathrm{II}}\right.$-bitapy-PBA)(DMSO) $\mathrm{Cl}_{2}\left(M_{\mathrm{n}(\mathrm{SEC})}, 11400\right.$; $34.0 \mathrm{mg}, 3.0 \mu \mathrm{mol})$ and $\mathrm{AgSbF}_{6}(3.0 \mathrm{mg}, 8.6 \mu \mathrm{mol})$ in acetone $(1.0 \mathrm{ml})$ was heated in a $10-\mathrm{ml}$ needle flask at $65{ }^{\circ} \mathrm{C}$ for $12 \mathrm{~h}$. Followed by filtration of the precipitated $\mathrm{AgCl}$, the solvent was removed to give ( $\mathrm{Ru}\left(\mathrm{PS}^{\mathrm{II}}\right.$-bitapy-PBA) $\left.(\mathrm{DMSO})\left(\mathrm{COMe}_{2}\right)_{2}\right)\left(\mathrm{SbF}_{6}\right)_{2}$ as a yellow solid. The intermediate $\left(\mathrm{Ru}\left(\mathrm{PS}^{\mathrm{II}}\right.\right.$ bitapy-PBA)(DMSO) $\left.\left(\mathrm{COMe}_{2}\right)_{2}\right)\left(\mathrm{SbF}_{6}\right)_{2}$ was then dissolved in acetone $(2.0 \mathrm{ml})$ and added to a $10-\mathrm{ml}$ needle flask containing one molar ratio of PSO-tapy $\left(M_{\mathrm{n}(\mathrm{SEC})}, 4400 ; 13.2 \mathrm{mg}, 3.0 \mu \mathrm{mol}\right)$. The reaction mixture was heated at $65^{\circ} \mathrm{C}$ for $24 \mathrm{~h}$. After cooling to room temperature, the reaction mixture was filtered, then purified by preparative SEC using THF as the eluent to give $\left(\mathrm{Ru}\left(\mathrm{PS}^{\mathrm{II}}\right.\right.$-bitapy-PBA)(PSO-tapy)(DMSO) $\left(\mathrm{SbF}_{6}\right)_{2}$ as a yellow solid $(38.7 \mathrm{mg}$, $82.0 \%) . M_{\mathrm{n}(\mathrm{SEC})}, 16800 ; M_{\mathrm{w}} / M_{\mathrm{n}}, 1.11$.
Preparation of $\left(\mathrm{Ru}\left(\mathrm{PS}^{\mathrm{II}}\right.\right.$-bitapy-PBA)$\left(\mathrm{PCL}^{\mathrm{II}}\right.$-tapy $\left.)(\mathrm{DMSO})\right)\left(\mathrm{SbF}_{6}\right)_{2}$ Method $\mathrm{E}$ was used with $\mathrm{Ru}\left(\mathrm{PS}^{\mathrm{II}}\right.$-bitapy-PBA)(DMSO) $\mathrm{Cl}_{2}\left(M_{\mathrm{n} \text { (SEC) }}, 11400\right.$, $34.0 \mathrm{mg}, 3.0 \mu \mathrm{mol}), \mathrm{AgSbF}_{6}(3.0 \mathrm{mg}, 8.6 \mu \mathrm{mol})$ and $\mathrm{PCL}^{\mathrm{II}}$-tapy $\left(M_{\mathrm{n}(\mathrm{NMR})}, 7400\right.$; $22.2 \mathrm{mg}, 3.0 \mu \mathrm{mol}$ ) The crude product was purified by preparative SEC using $\mathrm{CHCl}_{3}$ as the eluent to yield (Ru(PS ${ }^{\mathrm{II}}$-bitapy-PBA)(PCL ${ }^{\mathrm{II}}$-tapy)(DM$\mathrm{SO})\left(\mathrm{SbF}_{6}\right)_{2}$ as a yellow solid $(36.0 \mathrm{mg}, 64.0 \%) . M_{\mathrm{n}(\mathrm{SEC})}, 25600 ; M_{\mathrm{w}} / M_{\mathrm{n}}, 1.12$.

Preparation of $\left(\mathrm{Ru}\left(\mathrm{PS}^{\mathrm{II}}\right.\right.$-bitapy-PBA $)\left(\mathrm{PSO}-\right.$ bitapy-PCL $\left.\left.{ }^{\mathrm{I}}\right)\right)\left(\mathrm{SbF}_{\mathbf{6}}\right)_{2}$ Method E was used with $\mathrm{Ru}\left(\mathrm{PS}^{\mathrm{II}}\right.$-bitapy-PBA)$(\mathrm{DMSO}) \mathrm{Cl}_{2}\left(M_{\mathrm{n}(\mathrm{SEC})}\right), 11400$; $34.0 \mathrm{mg}, 3.0 \mu \mathrm{mol}), \mathrm{AgSbF}_{6}(3.0 \mathrm{mg}, 8.6 \mu \mathrm{mol})$, acetone $(1.5 \mathrm{ml})$ and PSObitapy-PCL ${ }^{\mathrm{I}}\left(M_{\mathrm{n}(\mathrm{NMR})}, 11600 ; 34.8 \mathrm{mg}, 3.0 \mu \mathrm{mol}\right)$ to yield (Ru(PS${ }^{\mathrm{II}}$-bitapyPBA)(PSO-bitapy-PCL $\left.\left.{ }^{\mathrm{I}}\right)\right)\left(\mathrm{SbF}_{6}\right)_{2}$ as a yellow solid $(34.8 \mathrm{mg}, 50.6 \%) . M_{\mathrm{n}(\mathrm{SEC})}$, $26500 ; M_{\mathrm{w}} / M_{\mathrm{n}}, 1.11$.

\section{RESULTS AND DISCUSSION}

Synthesis of polymer-substituted tapy and bitapy ligands

To obtain the polymer-substituted tapy and bitapy ligands, the azidoterminated arm polymers were first prepared, as shown in Scheme 2. Table 1 summarizes the synthetic results for the azido-terminated arm polymers. All polymer yields were reasonable in the range of $73.0-94.4 \%$, and the molecular weights $\left(M_{\mathrm{n}(\mathrm{NMR})} \mathrm{s}\right)$ estimated by the ${ }^{1} \mathrm{H}$ NMR measurements were 2900-7400. The azido-terminated PS (PS- $\left.\mathrm{N}_{3}\right)$ and PBA $\left(\mathrm{PBA}-\mathrm{N}_{3}\right)$ were prepared by the reaction of the (PS-Br) and PBA (PBA-Br), which were synthesized by the atomtransfer radical polymerizations of styrene $(\mathrm{S})$ and $n$-butyl acrylate (BA) using ethyl 2-bromoisobutyrate, respectively, with $\mathrm{NaN}_{3}$. The degree of polymerizations (DPs) of $\mathrm{PS}^{\mathrm{I}}-\mathrm{N}_{3}$ and $\mathrm{PS}^{\mathrm{II}}-\mathrm{N}_{3}$ were 26.4 (run 1) and 44.3 (run 2), respectively, and that of PBA- $\mathrm{N}_{3}$ was 43.2 (run 3). For the synthesis of the azido-terminated PCLs (PCL-N ${ }_{3}$ )s and the azido-terminated poly(SO) $\left(\mathrm{PSO}-\mathrm{N}_{3}\right)$, the controlled/living ringopening polymerizations of $\varepsilon$-caprolactone using diphenyl phosphate and of SO using the phosphazene base of $t-\mathrm{Bu}-\mathrm{P}_{4}$ were carried out, employing 6-azido-1-hexanol as the initiator for both of the two ringopening polymerizations, respectively. ${ }^{22-23}$ The DPs of PCL ${ }^{\mathrm{I}}-\mathrm{N}_{3}$ and $\mathrm{PCL}^{\mathrm{II}}-\mathrm{N}_{3}$ were 47.2 (run 4) and 63.8 (run 5), respectively, and that of PSO- $\mathrm{N}_{3}$ was 52.1 (run 6). All the molecular weight distributions $\left(M_{\mathrm{w}} / M_{\mathrm{n}}\right) \mathrm{s}$ were between 1.09-1.13. In addition, the azido-terminated PHIC (PHIC-N ${ }_{3}$ ) was prepared by the living coordination polymerization of $n$-hexyl isocyanate using dichloro(cyclopentadienyl)(6azidohexyloxy)titanium that was prepared by mixing 6-azido-1hexanol with trichloro(cyclopentadienyl)titanium before the polymerization. The DP of PHIC-N $\mathrm{N}_{3}$ was 40.4 (run 7), and the $M_{\mathrm{w}} / M_{\mathrm{n}}$ was as low as 1.09, as shown in Figure 1. The characteristic signals due to the initiator residue of 6-azido-1-hexanol were observed at 3.30 and 4.21 p.p.m. along with the PHIC chain, as shown in the ${ }^{1} \mathrm{H}$ NMR spectrum (Figure 2a). In addition, the characteristic stretching signals of the azido group was confirmed in the FTIR spectrum (Figure 3a). In order to provide further insight into the polymer structure of PHIC-N $\mathrm{N}_{3}$, a MALDI-TOF MS measurement of PHIC- $\mathrm{N}_{3}$ was carried out. A main and sub series of peaks were observed, as shown in Figure 4a. The peak interval between the main series was 127.1, which is identical to the molecular weight of $n$-hexyl isocyanate. Additionally, the main peak at $3514.5(\mathrm{~m} / \mathrm{z})$ is in good agreement with the theoretical isotopic molecular weight of the sodium-cationized PHIC $(n=26)$ with the azido end $\left(\mathrm{C}_{190} \mathrm{H}_{353} \mathrm{O}_{28} \mathrm{~N}_{29} \mathrm{Na}\right.$ : 3514.71). The small sub peaks were attributed to those of the denitrogenized product, which were produced during the ionization process. These results clearly indicated that the azido group was quantitatively introduced into the PHIC chain end. The characteristics of the ${ }^{1} \mathrm{H}$ NMR, FTIR, MALDI-TOF MS spectra and SEC measurements for the obtained 


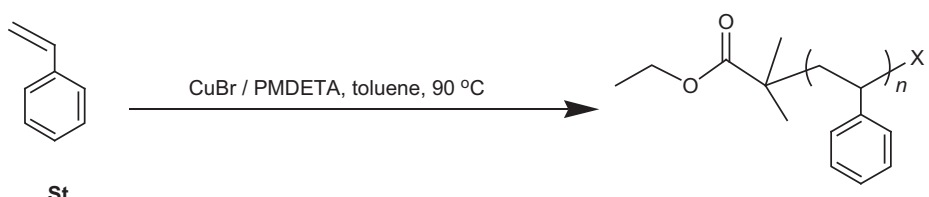

St

$$
\begin{array}{ll}
\mathrm{NaN}_{3}, \text { DMF, r.t. } \quad \longrightarrow \text { PS-Br }(\mathrm{X}=\mathrm{Br}) \\
\hline & \text { PS- } \mathrm{N}_{3}\left(\mathrm{X}=\mathrm{N}_{3}\right)
\end{array}
$$
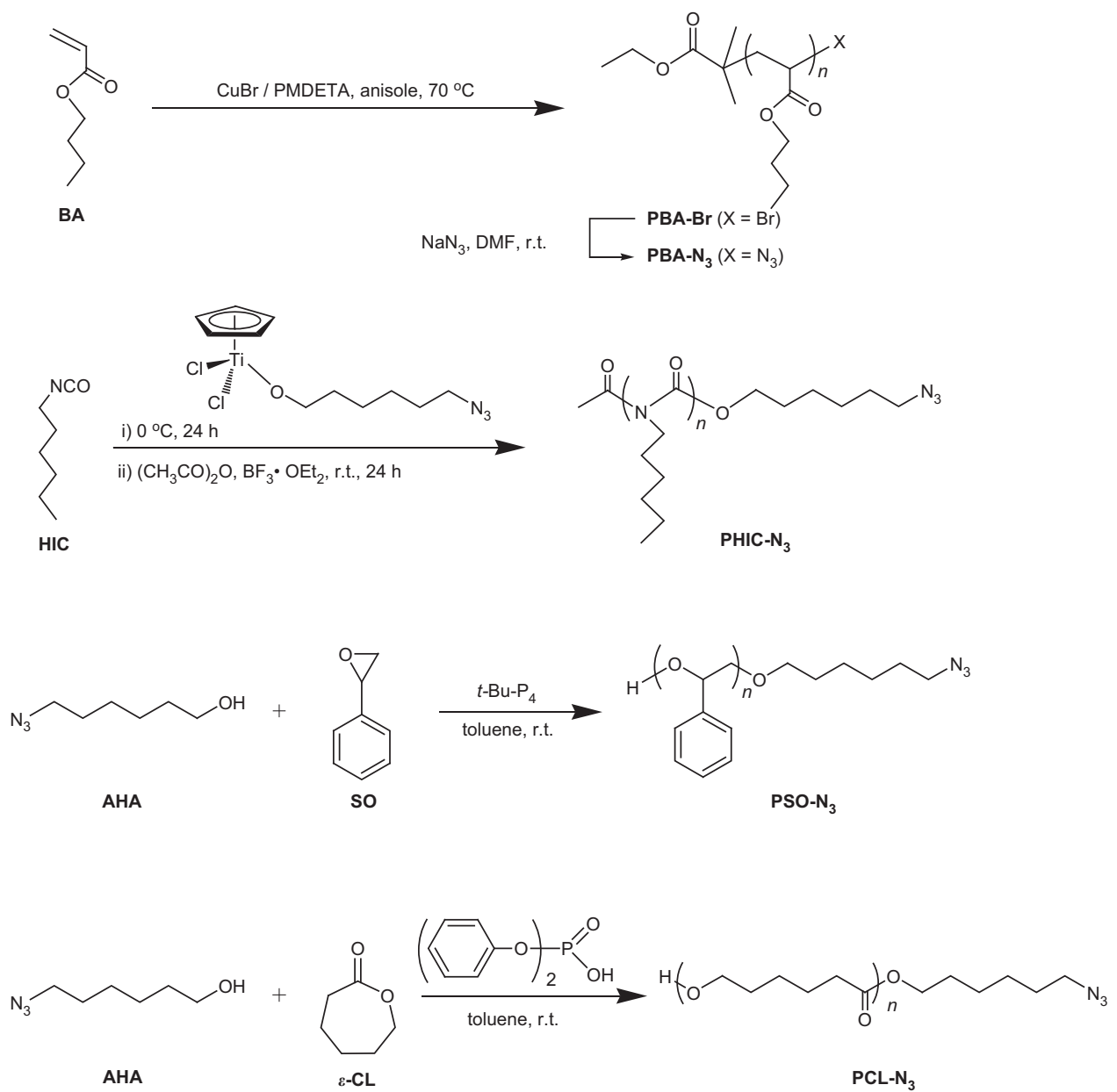

Scheme 2 Synthesis of azido-terminated polystyrene (PS- $\left.N_{3}\right)$, poly $\left(n\right.$-butyl acrylate) (PBA- $\left.N_{3}\right)$, poly $\left(n\right.$-hexyl isocyanate) (PHIC- $\left.N_{3}\right)$, poly(styrene oxide) (PSO$\mathrm{N}_{3}$ ) and poly $\left(\varepsilon\right.$-caprolactone) $\left(\mathrm{PCL}-\mathrm{N}_{3}\right)$.

Table 1 Synthesis of azido-terminated polymers.

\begin{tabular}{|c|c|c|c|c|c|}
\hline Run & Polymers & Yield (\%) & $M_{n(N M R)}(D P)^{a}$ & $M_{n(S E C)}$ & $M_{w} / M_{n}$ \\
\hline 1 & $P S^{\prime}-N_{3}$ & 87.0 & $2900(26.4)$ & $2800^{b}$ & $1.13^{\mathrm{b}}$ \\
\hline 2 & $P S^{I I}-N_{3}$ & 89.5 & $4800(44.3)$ & $4700^{c}$ & $1.12^{\mathrm{c}}$ \\
\hline 3 & $\mathrm{PBA}-\mathrm{N}_{3}$ & 91.4 & $5700(43.2)$ & $4700^{c}$ & $1.12^{\mathrm{c}}$ \\
\hline 4 & $P C L^{\prime}-\mathrm{N}_{3}$ & 94.4 & $5500(47.2)$ & $9300^{c}$ & $1.09^{c}$ \\
\hline 5 & $P C L^{I I}-N_{3}$ & 90.5 & $7400(63.8)$ & $13800^{c}$ & $1.11^{\mathrm{c}}$ \\
\hline 6 & $\mathrm{PSO}-\mathrm{N}_{3}$ & 85.0 & $6400(52.1)$ & $4600^{\circ}$ & $1.13^{\mathrm{c}}$ \\
\hline 7 & $\mathrm{PHIC}-\mathrm{N}_{3}$ & 73.0 & $5300(40.4)$ & $3900^{b}$ & $1.09^{b}$ \\
\hline
\end{tabular}

Abbreviation: DP, degree of polymerization.

a Determined by ${ }^{1} \mathrm{H}$ NMR in $\mathrm{CDCl}_{3}$.

${ }^{\text {b}}$ Determined by SEC in THF using polystyrenes (PS) standards.

cDetermined by SEC in $\mathrm{CHCl}_{3}$ using PS standards.
PS-Br, PBA-Br, PS- $\mathrm{N}_{3}$, PBA- $\mathrm{N}_{3}$, PSO-N $\mathrm{N}_{3}$ and PCL- $\mathrm{N}_{3}$ are displayed in Supplementary Figures S1-12 and 14-16.

The polymer-substituted tapy and bitapy ligands were synthesized by the click reaction of the azido-terminated polymers with ethynylpyridines, as illustrated in Scheme 3. Table 2 summarizes the synthetic results of tapy and bitapy ligands. For the synthesis of the polymersubstituted tapy ligands, we previously reported the click reaction of PS- $\mathrm{N}_{3}$ with 2-ethynylpyridine using CuBr/PMDETA in THF to produce the 2-(1-PS- $1 H-1,2,3$-triazol-4-yl)pyridine (PS-tapy). ${ }^{15}$ In this study, the PS ${ }^{\mathrm{I}}$-tapy with the $M_{\mathrm{n} \text { (NMR) }}$ of 3000 was obtained in the high yield of $90 \%$ (run 8). Similarly, the 2-(1-PCL- $1 H-1,2$, 3-triazol-4-yl)pyridine, 2-(1-poly(SO)-1H-1,2,3-triazol-4-yl)pyridine and 2-(1-PHIC-1H-1,2,3-triazol-4-yl)pyridine (PCL ${ }^{\mathrm{II}}$-tapy, PSO-tapy and PHIC-tapy, respectively) were prepared using $\mathrm{PCL}^{\mathrm{II}}-\mathrm{N}_{3}, \mathrm{PSO}-\mathrm{N}_{3}$ 


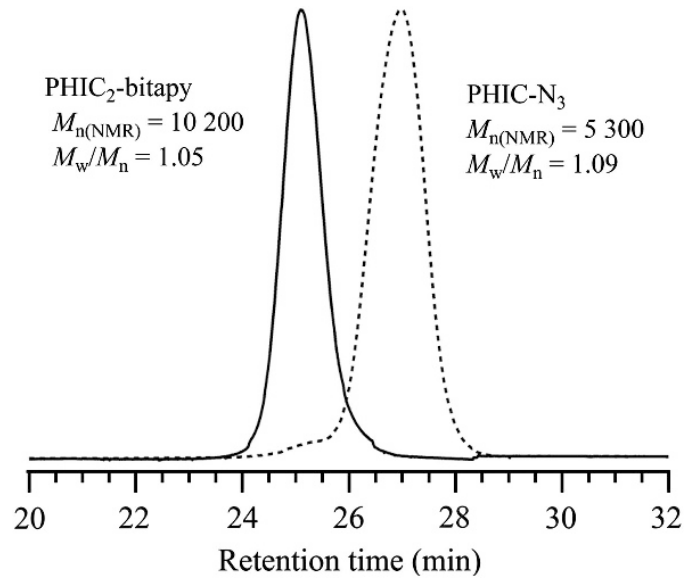

Figure 1 SEC traces of PHIC-N $\mathrm{N}_{3}$ and $\mathrm{PHIC}_{2}$-bitapy determined in $\mathrm{THF}$ at a flow of $1.0 \mathrm{ml} \mathrm{min}^{-1}$.

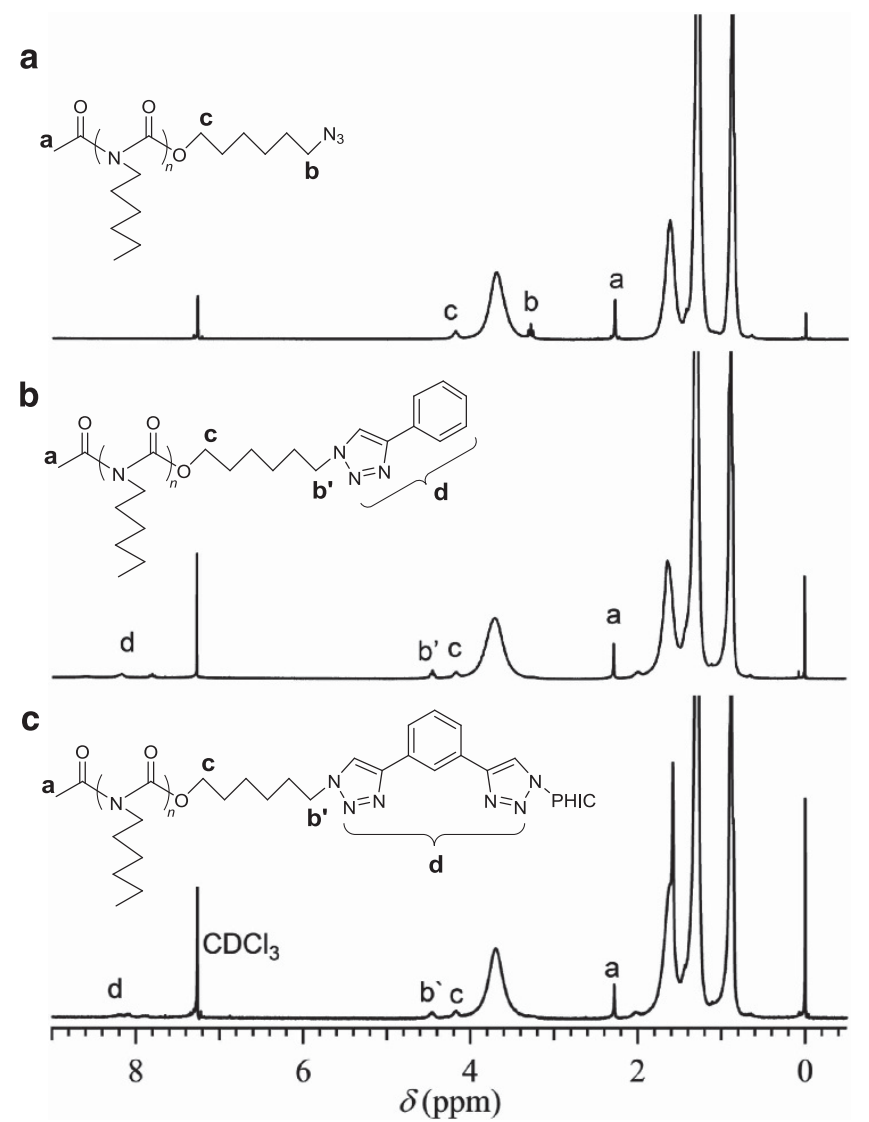

Figure $2{ }^{1} \mathrm{H}$ NMR spectra of (a) PHIC-N ${ }_{3}$, (b) PHIC-tapy and (c) $\mathrm{PHIC}_{2^{-}}$ bitapy determined in $\mathrm{CDCl}_{3}$.

and PHIC- $\mathrm{N}_{3}$, respectively, in the good yields of 90.2-92.0\% (runs 9-11). The $M_{\mathrm{n}}$ (NMR) showed no obvious difference, and the $M_{\mathrm{w}} / M_{\mathrm{n}}$ remained narrow from PHIC- $\mathrm{N}_{3}$ to PHIC-tapy $\left(M_{\mathrm{w}} / M_{\mathrm{n}}=1.09\right)$. In the ${ }^{1} \mathrm{H}$ NMR spectrum (Figure $2 b$ ), the new signals due to the tapy group were observed in the range of 7.80-8.43 p.p.m. along with the PHIC chain. Additionally, the signals of the methylene protons neighboring the azido group shifted from 3.30 p.p.m. to 4.43 p.p.m. after the click reaction with 2-ethynylpyridine. In the FTIR spectrum (Figure $3 \mathrm{~b}$ ), the characteristic stretching signals of the azido group

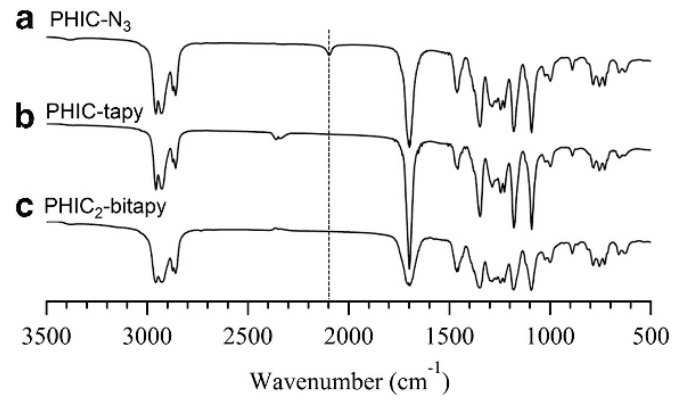

Figure 3 IR spectra of (a) PHIC-N ${ }_{3}$, (b) PHIC-tapy and (c) PHIC-bitapy.

due to PHIC- $\mathrm{N}_{3}$ disappeared after the click reaction with 2-ethynylpyridine. The PHIC-tapy structure was further confirmed by a MALDI-TOF MS measurement. Only one series of peaks was observed, as shown in Figure $4 \mathrm{~b}$. The peak interval of 127.1 is identical to the molecular weight of $n$-hexyl isocyanate. The main peak at $3617.5(\mathrm{~m} / \mathrm{z})$ is in good agreement with the theoretical isotopic molecular weight of the sodium-cationized PHIC $(n=26)$ with the tapy chain end $\left(\mathrm{C}_{197} \mathrm{H}_{358} \mathrm{O}_{28} \mathrm{~N}_{30} \mathrm{Na}\right.$ : 3617.75). For PS ${ }^{\mathrm{I}}$-tapy, PCL ${ }^{\mathrm{II}}$-tapy and PSO-tapy, the SEC traces, ${ }^{1} \mathrm{H}$ NMR and FTIR spectra, and MALDI-TOF MS measurements are shown in Supplementary Figures S1, 3-5, 7-9, 11-12 and 16.

The synthesis of 2,6-bis(1-PHIC-1H-1,2,3-triazol-4-yl)pyridine ( $\mathrm{PHIC}_{2}$-bitapy) was obtained from $\mathrm{PHIC}-\mathrm{N}_{3}$ and 2,6-diethynylpyridine according to the procedure similar to that for the synthesis of $\mathrm{PS}_{2}{ }_{2}$-bitapy reported in our previous study. ${ }^{15}$ The click reaction between PHIC- $\mathrm{N}_{3}$ and 2,6-diethynylpyridine was carried out at the molar ratio of $\left(\mathrm{PHIC}-\mathrm{N}_{3}\right) /(2,6$-diethynylpyridine $)=2$. After the click reaction, the SEC trace shifted to the higher molecular weight region, as shown in Figure 1, and the $M_{\mathrm{n}(\mathrm{NMR})}$ of $\mathrm{PHIC}_{2}$-bitapy was almost twice that of PHIC- $\mathrm{N}_{3}$. In the ${ }^{1} \mathrm{H}$ NMR spectrum (Figure 2c), the new signals due to the bitapy group were observed in the range of 7.74-8.25 p.p.m. along with the PHIC chain. In the FTIR spectrum (Figure $3 \mathrm{c}$ ), the characteristic stretching signals of the azido group due to the reactant, PHIC- $\mathrm{N}_{3}$, completely disappeared after the click reaction with 2,6-diethynylpyridine. These results clearly indicated that the bitapy group was introduced into the center of the $\mathrm{PHIC}_{2}$ bitapy chain. For $\mathrm{PS}_{2}^{\mathrm{I}}$-bitapy, the characteristics of the SEC trace, ${ }^{1} \mathrm{H}$ NMR and FTIR spectra, and MALDI-TOF MS measurement are shown in Supplementary Figures S1, 5, 9 and 14.

For the synthesis of the block copolymer-substituted bitapy ligands, the click reaction was carried out twice using two different azidoterminated polymers. The 2-ethynyl-6-(1-PS ${ }^{\mathrm{II}}-1 H-1,2,3$-triazol-4yl)pyridine ( $\mathrm{PS}^{\mathrm{II}}$-etapy) was first prepared by the click reaction between an excess amount of 2,6-diethynylpyridine and $\mathrm{PS}^{\mathrm{II}}-\mathrm{N}_{3}$ in 92.5\% yield, and then $\mathrm{PS}^{\mathrm{II}}$-etapy was further reacted with $\mathrm{PBA}-\mathrm{N}_{3}$ to afford the 2-(1-PS-1H-1,2,3-triazol-4-yl)-6-(1-PBA-1H- 1,2,3-triazol4 -yl)pyridine (PS ${ }^{\mathrm{II}}$-bitapy-PBA) with a yield of $76.5 \%$. Using the same procedure, the 2-(1-poly(SO)-1H-1,2,3-triazol-4-yl)-6-(1-PCL $\mathrm{I}-1 H$ $1,2,3$-triazol-4-yl)pyridine (PSO-bitapy-PCL ${ }^{\mathrm{I}}$ ) was obtained in a yield of $79.4 \%$. For the structural confirmation of the $\mathrm{PS}^{\mathrm{II}}$-etapy, PSO-etapy, PS ${ }^{\mathrm{II}}$-bitapy-PBA and PSO-bitapy-PCL ${ }^{\mathrm{I}}$, the characteristics of the SEC traces, ${ }^{1} \mathrm{H}$ NMR and FTIR spectra, and MALDI-TOF MS measurements are shown in Supplementary Figures S1, 3, 6-7, 10-11, $15-16$.

\section{Synthesis of miktoarm star copolymers}

We previously reported the one-pot synthesis of three- and fourarmed star-shaped PS $\mathrm{Ru}(\mathrm{II})$ complexes, $\left(\mathrm{Ru}(\mathrm{PS} \text {-tapy })_{3}\right)\left(\mathrm{PF}_{6}\right)_{2}$ and 

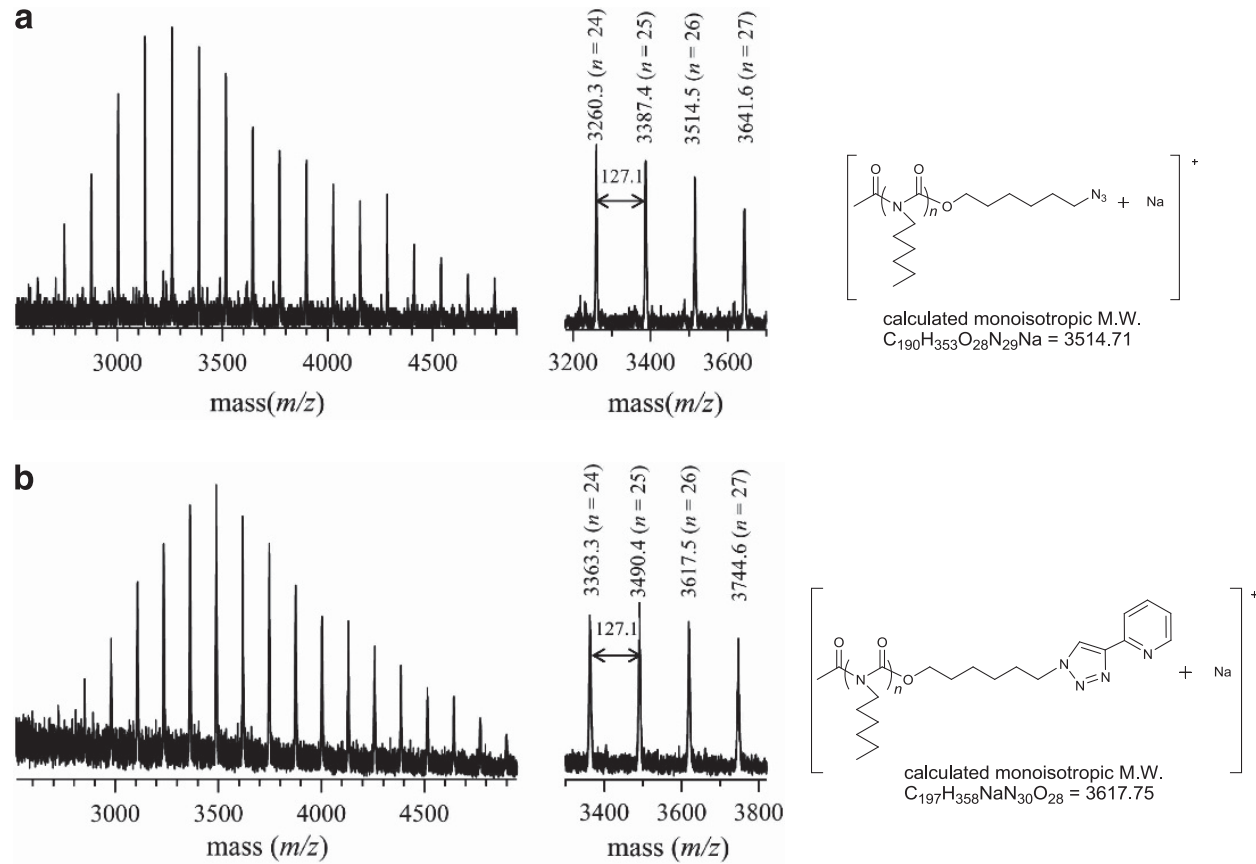

Figure 4 MALDI-TOF MS spectra (reflector mode) of (a) PHIC- $\mathrm{N}_{3}$ and (b) PHIC-tapy.

$\left(\mathrm{Ru}\left(\mathrm{PS}_{2} \text {-bitapy }\right)_{2}\right)\left(\mathrm{PF}_{6}\right)_{2}$, by the chelating reaction between PS-tapy and $\mathrm{PS}_{2}$-bitapy with $\mathrm{Ru}(\mathrm{II})$ that was obtained from the reducing reaction of $\mathrm{Ru}(\mathrm{III}) \mathrm{Cl}_{3}$, respectively. ${ }^{15}$ We now examined the preparation of $\left(\mathrm{Ru}(\mathrm{PS} \text {-tapy })_{3}\right)\left(\mathrm{SbF}_{6}\right)_{2}$ and $\left(\mathrm{Ru}\left(\mathrm{PS}_{2} \text {-bitapy }\right)_{2}\right)\left(\mathrm{SbF}_{6}\right)_{2}$ by the stepwise chelating method as model reactions, as illustrated in Scheme 1, to confirm the feasibility of the stepwise chelating method for synthesizing miktoarm star copolymers. $\mathrm{PS}^{\mathrm{I}}$-tapy and $\mathrm{PS}_{2}^{\mathrm{I}}{ }_{2}$-bitapy were reacted with $\mathrm{Ru}(\mathrm{II})(\mathrm{DMSO})_{4} \mathrm{Cl}_{2}$ in chloroform at $65^{\circ} \mathrm{C}$ to produce their stable $\mathrm{Ru}(\mathrm{II})$ mono-complexes, $\mathrm{Ru}\left(\mathrm{PS}^{\mathrm{I}}\right.$-tapy)(DM$\mathrm{SO})_{2} \mathrm{Cl}_{2}$ and $\mathrm{Ru}\left(\mathrm{PS}_{2}{ }_{2}\right.$-bitapy)(DMSO$) \mathrm{Cl}_{2}$, respectively. The chelating reactions of $\mathrm{PS}^{\mathrm{I}}$-tapy with $\mathrm{Ru}\left(\mathrm{PS}^{\mathrm{I}} \text {-tapy)(DMSO }\right)_{2} \mathrm{Cl}_{2}$ and $\mathrm{PS}_{2}{ }_{2}$-bitapy with $\mathrm{Ru}\left(\mathrm{PS}_{2}^{\mathrm{I}}{ }_{2}\right.$-bitapy)(DMSO) $\mathrm{Cl}_{2}$ were then further carried out to afford $\left(\mathrm{Ru}\left(\mathrm{PS}^{\mathrm{I}} \text {-tapy }\right)_{3}\right)\left(\mathrm{SbF}_{6}\right)_{2}$ (run 16) and $\left(\mathrm{Ru}\left(\mathrm{PS}_{2}{ }_{2} \text {-bitapy }\right)_{2}\right)\left(\mathrm{SbF}_{6}\right)_{2}$ (run 22), respectively. Table 3 lists the synthetic results. After removal of the unreacted polymeric ligands, the molecular weights $\left(M_{\mathrm{n}(\mathrm{SEC})}\right)$ of $\left(\mathrm{Ru}\left(\mathrm{PS}^{\mathrm{I}} \text {-tapy }\right)_{3}\right)\left(\mathrm{SbF}_{6}\right)_{2}$ (run 16) and $\left(\mathrm{Ru}\left(\mathrm{PS}_{2}{ }_{2} \text {-bitapy }\right)_{2}\right)\left(\mathrm{SbF}_{6}\right)_{2}$ (run 22) were 8200 and 14800 , respectively, which indicated the obvious enhancement relative to their chelating arms, PS-tapy (run 8; $M_{\mathrm{n}(\mathrm{SEC})}=3100, \quad M_{\mathrm{w}} / M_{\mathrm{n}}=1.13$ ) and $\mathrm{PS}_{2}{ }_{2}$-bitapy (run 12; $\left.M_{\mathrm{n}(\mathrm{SEC})}=6400, M_{\mathrm{w}} / M_{\mathrm{n}}=1.07\right)$, respectively. The shifts in the SEC traces to the higher molecular weight region in Supplementary Figure S18 provided the direct evidence for the formation of the three- and four-armed PS ${ }^{I} \mathrm{Ru}(\mathrm{II})$ complexes. The formation of star-shaped PS $\mathrm{Ru}$ (II) complexes was also proven by ${ }^{1} \mathrm{H}$ NMR spectra, as shown in Supplementary Figure S13. A broadening effect of the proton signals due to the tapy groups was clearly observed after the formation of the $\mathrm{Ru}$ (II) complex, which should be attributed to the strong coordinating interaction between $\mathrm{Ru}(\mathrm{II})$ and the tapy groups.

For the ABC-type miktoarm star copolymer $\mathrm{Ru}(\mathrm{II})$ complexes, $\left(\mathrm{Ru}\left(\mathrm{PS}^{\mathrm{II}}\right.\right.$-bitapy-PBA)$\left(\mathrm{PCL}^{\mathrm{II}}\right.$-tapy) (DMSO) $\left(\mathrm{SbF}_{6}\right)_{2} \quad$ (run 20) and $\left(\mathrm{Ru}\left(\mathrm{PS}^{\mathrm{II}}\right.\right.$-bitapy-PBA)(PSO-tapy)(DMSO) $)\left(\mathrm{SbF}_{6}\right)_{2}$ (run 21) were prepared from $\mathrm{Ru}\left(\mathrm{PS}^{\mathrm{II}}\right.$-bitapy-PBA)(DMSO) $\mathrm{Cl}_{2}$ with $\mathrm{PCL}^{\mathrm{II}}$-tapy and PSO-tapy, respectively. The $M_{\mathrm{n}(\mathrm{SEC}) \mathrm{S}}$ of ( $\mathrm{Ru}\left(\mathrm{PS}^{\mathrm{II}}\right.$-bitapy-PBA) $\left(\mathrm{PCL}^{\mathrm{II}}\right.$-tapy) $\left.(\mathrm{DMSO})\right)\left(\mathrm{SbF}_{6}\right)_{2}$ and (Ru(PS ${ }^{\mathrm{II}}$-bitapy-PBA)(PSO-tapy)
$(\mathrm{DMSO}))\left(\mathrm{SbF}_{6}\right)_{2}$ were 25600 and 16800 , respectively. The SEC traces of $\left(\mathrm{Ru}\left(\mathrm{PS}^{\mathrm{II}}\right.\right.$-bitapy-PBA)$\left(\mathrm{PCL}^{\mathrm{II}}\right.$-tapy) $\left.(\mathrm{DMSO})\right)\left(\mathrm{SbF}_{6}\right)_{2}$ and $\left(\mathrm{Ru}\left(\mathrm{PS}^{\mathrm{II}}\right.\right.$ bitapy-PBA)(PSO-tapy)(DMSO) $\left(\mathrm{SbF}_{6}\right)_{2}$ after the $\mathrm{Ru}(\mathrm{II})$ complexation displayed an obvious shift to the higher molecular weight region relative to that of $\mathrm{PS}^{\mathrm{II}}$-bitapy-PBA, as shown in Figure 5. The ${ }^{1} \mathrm{H}$ NMR spectra in Figure 6 showed both the signals assignable to the $\mathrm{PS}^{\mathrm{II}}$ and PBA segments along with the $\mathrm{PCL}^{\mathrm{II}}$ one in $\left(\mathrm{Ru}\left(\mathrm{PS}^{\mathrm{II}}\right.\right.$-bitapy$\mathrm{PBA})\left(\mathrm{PCL}^{\mathrm{II}}\right.$-tapy)(DMSO)$)\left(\mathrm{SbF}_{6}\right)_{2}$ and the $\mathrm{PS}^{\mathrm{II}}$ and $\mathrm{PBA}$ segments along with the $\mathrm{PSO}$ one in $\left(\mathrm{Ru}\left(\mathrm{PS}^{\mathrm{II}}\right.\right.$-bitapy-PBA)(PSO-tapy)(DM$\mathrm{SO})\left(\mathrm{SbF}_{6}\right)_{2}$. These results indicated the formation of the ABC-type miktoarm star copolymers $\mathrm{Ru}(\mathrm{II})$ complexes, (Ru(PSI-bitapy$\mathrm{PBA})\left(\mathrm{PCL}^{\mathrm{II}}\right.$-tapy) (DMSO)) $\left(\mathrm{SbF}_{6}\right)_{2}$ and (Ru(PS ${ }^{\mathrm{II}}$-bitapy-PBA)(PSOtapy) (DMSO) $\left(\mathrm{SbF}_{6}\right)_{2}$.

For the ABCD-type miktoarm star copolymer $\mathrm{Ru}(\mathrm{II})$ complex, $\left(\mathrm{Ru}\left(\mathrm{PS}^{\mathrm{II}}\right.\right.$-bitapy-PBA)(PSO-bitapy-PCL $\left.\left.{ }^{\mathrm{I}}\right)\right)\left(\mathrm{SbF}_{6}\right)_{2}$ was prepared from $\mathrm{Ru}\left(\mathrm{PS}^{\mathrm{II}}\right.$-bitapy-PBA)(DMSO) $\mathrm{Cl}_{2}$ with PSO-bitapy-PCL ${ }^{\mathrm{I}}$. The $M_{\mathrm{n} \text { (SEC) }}$ of the obtained (Ru(PS ${ }^{\mathrm{II}}$-bitapy-PBA) (PSO-bitapy$\left.\left.\mathrm{PCL}^{\mathrm{I}}\right)\right)\left(\mathrm{SbF}_{6}\right)_{2}$ was 26500 , which fairly agreed with the addition of the $M_{\mathrm{n}(\mathrm{SEC})} \mathrm{S}$ of $\mathrm{PS}^{\mathrm{II}}$-bitapy-PBA and PSO-bitapy-PCL $\mathrm{P}^{\mathrm{I}}$, that is, $\left(M_{\mathrm{n}(\mathrm{SEC})}\right.$ of PS ${ }^{\mathrm{II}}$-bitapy-PBA $)+\left(M_{\mathrm{n}(\mathrm{SEC})}\right.$ of PSO-bitapy-PCL $\left.{ }^{\mathrm{I}}\right)=25$ 900. The SEC trace of (Ru(PSII-bitapy-PBA)(PSO-bitapy$\left.\left.\mathrm{PCL}^{\mathrm{I}}\right)\right)\left(\mathrm{SbF}_{6}\right)_{2}$ after the $\mathrm{Ru}(\mathrm{II})$ complexation, as shown in Figure 5, displayed an obvious shift to the higher molecular weight region relative to that of the precursor, $\mathrm{PS}^{\mathrm{II}}$-bitapy-PBA. In the ${ }^{1} \mathrm{H}$ NMR spectra of Figure 6, the signals assignable to the PS ${ }^{\mathrm{II}}, \mathrm{PBA}, \mathrm{PSO}$ and $\mathrm{PCL}^{\mathrm{I}}$ segments were simultaneously observed. These results indicated the formation of the $\mathrm{Ru}(\mathrm{II})$ complexes.

Using the same stepwise chelating method, the $\mathrm{AB}_{2}$-type miktoarm star-shaped copolymer $\mathrm{Ru}(\mathrm{II})$ complexes, (Ru(PS ${ }^{\mathrm{I}}$-tapy)(PHICtapy $\left.)_{2}\right)\left(\mathrm{SbF}_{6}\right)_{2}$ (run 17), (Ru(PS ${ }^{\mathrm{I}}$-tapy $)_{2}(\mathrm{PHIC}$-tapy) $)\left(\mathrm{SbF}_{6}\right)_{2}$ (run $18)$ and $\left(\mathrm{Ru}\left(\mathrm{PS}_{2}{ }_{2}\right.\right.$-bitapy)(PSO-tapy)(DMSO) $\left(\mathrm{SbF}_{6}\right)_{2}$ (run 19), were prepared from $\mathrm{Ru}\left(\mathrm{PS}^{\mathrm{I}}\right.$-tapy)(DMSO) ${ }_{2} \mathrm{Cl}_{2}$ and PHIC-tapy (molar ratio, 1:2), $\mathrm{Ru}\left(\mathrm{PHIC}\right.$-tapy)(DMSO) ${ }_{2} \mathrm{Cl}_{2}$ and $\mathrm{PS}^{\mathrm{I}}$-tapy (molar ratio, $1: 2)$, and $\mathrm{Ru}\left(\mathrm{PS}_{2}^{\mathrm{I}}\right.$-bitapy)(DMSO) $\mathrm{Cl}_{2}$ and PSO-tapy (molar ratio, 

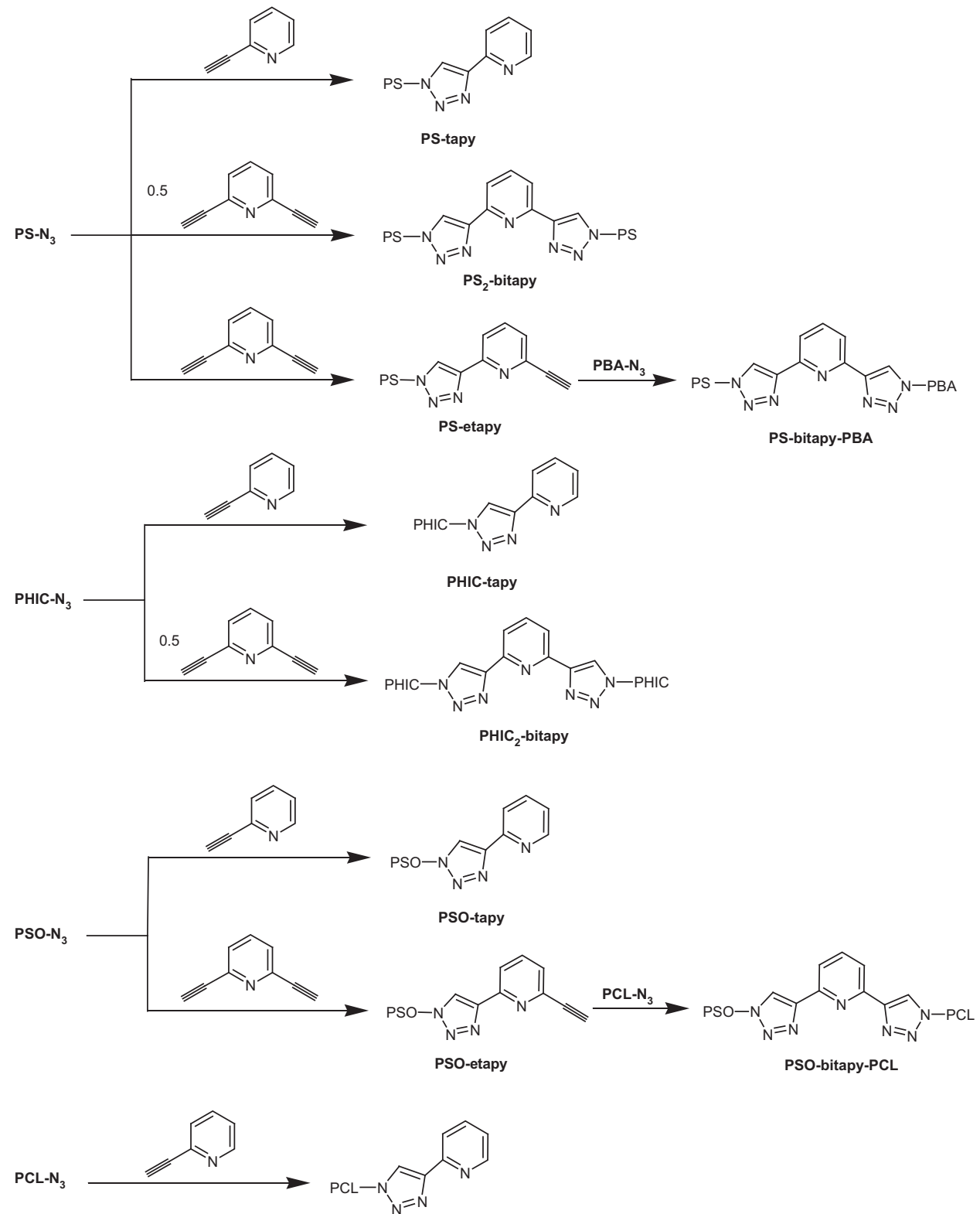

PCL-tapy

Scheme 3 Synthesis of tapy- and bitapy-functionalized arm polymers, PS-tapy, PS2-bitapy, PS-bitapy-PBA, PHIC-tapy, PHIC2-bitapy, PSO-tapy, PSO-bitapyPCL and PCL-tapy.

Table 2 Synthesis of tapy- and bitapy-functionalized arm polymers.

\begin{tabular}{|c|c|c|c|c|c|}
\hline run & Polymers & Yield (\%) & $M_{n(N M R)^{a}}$ & $M_{n(S E C)}$ & $M_{w} / M_{n}$ \\
\hline 8 & PS'-tapy & 91.0 & 3000 & $3100^{b}$ & $1.13^{\mathrm{b}}$ \\
\hline 9 & $P C L^{\text {II-tapy }}$ & 90.2 & 7600 & $13500^{c}$ & $1.20^{\mathrm{C}}$ \\
\hline 10 & PSO-tapy & 92.0 & 6500 & $4400^{c}$ & $1.26^{\mathrm{c}}$ \\
\hline 11 & PHIC-tapy & 92.0 & 5000 & $4000^{b}$ & $1.09^{b}$ \\
\hline 12 & $\mathrm{PS}_{2}{ }_{2}$-bitapy & 62.0 & 6200 & $6400^{b}$ & $1.07^{\mathrm{b}}$ \\
\hline 13 & $\mathrm{PHIC}_{2}$-bitapy & 69.0 & 10200 & $9900^{b}$ & $1.05^{\mathrm{b}}$ \\
\hline 14 & PS'-bitapy-PBA & 76.5 & 10800 & $11300^{c}$ & $1.15^{\mathrm{C}}$ \\
\hline 15 & PSO-bitapy-PCLI & 79.4 & 12200 & $14600^{c}$ & $1.18^{\mathrm{c}}$ \\
\hline
\end{tabular}

a Determined by ${ }^{1} \mathrm{H}$ NMR in $\mathrm{CDCl}_{3}$

betermined by size exclusion chromatography (SEC) in THF using polystyrenes (PS) standards. 'Determined by SEC in $\mathrm{CHCl}_{3}$ using PS standards.
$1: 1)$, respectively, the $(\mathrm{AB})_{2}$-type miktoarm star copolymer $\mathrm{Ru}(\mathrm{II})$ complex, $\left(\mathrm{Ru}\left(\mathrm{PS}^{\mathrm{II}} \text {-bitapy-PBA }\right)_{2}\right)\left(\mathrm{SbF}_{6}\right)_{2}$ (run 23), was prepared from $\mathrm{Ru}\left(\mathrm{PS}^{\mathrm{II}}\right.$-bitapy-PBA)(DMSO) $\mathrm{Cl}_{2}$ with $\mathrm{PS}^{\mathrm{II}}$-bitapy-PBA, and $\mathrm{A}_{2} \mathrm{~B}_{2}$ type miktoarm star copolymer $\mathrm{Ru}(\mathrm{II})$ complex, $\left(\mathrm{Ru}\left(\mathrm{PS}_{2}^{\mathrm{I}}\right.\right.$-bitapy) $\left(\mathrm{PHIC}_{2}\right.$-bitapy)) $\left(\mathrm{SbF}_{6}\right)_{2}$ (run 24), was prepared from $\mathrm{Ru}\left(\mathrm{PS}_{2^{-}}\right.$ bitapy)(DMSO)Cl ${ }_{2}$ with $\mathrm{PHIC}_{2}$-bitapy, respectively. The $M_{\mathrm{n}(\mathrm{SEC})^{\mathrm{S}}}$ of $\left(\mathrm{Ru}\left(\mathrm{PS}^{\mathrm{I}}\right.\right.$-tapy $\left.)(\mathrm{PHIC} \text {-tapy })_{2}\right)\left(\mathrm{SbF}_{6}\right)_{2}, \quad\left(\mathrm{Ru} \quad\left(\mathrm{PS}^{\mathrm{I}} \text {-tapy }\right)_{2}(\mathrm{PHIC}-\right.$ tapy) $\left(\mathrm{SbF}_{6}\right)_{2}, \quad\left(\mathrm{Ru}\left(\mathrm{PS}_{2}{ }_{2}\right.\right.$-bitapy)(PSO-tapy)(DMSO$\left.)\right)\left(\mathrm{SbF}_{6}\right)_{2}, \quad(\mathrm{Ru}(\mathrm{P}-$ $\mathrm{S}^{\mathrm{II}}$-bitapy-PBA $\left.)_{2}\right)\left(\mathrm{SbF}_{6}\right)_{2}$ and $\left(\mathrm{Ru}\left(\mathrm{PS}_{2}{ }_{2}\right.\right.$-bitapy $)\left(\mathrm{PHIC}_{2}\right.$-bitapy) $\left(\mathrm{SbF}_{6}\right)_{2}$ were 9 900, 9 500,12200, 21400 and 11900, respectively, which were in good agreement with the additional $M_{\mathrm{n}(\mathrm{SEC})} \mathrm{s}$ from their polymeric ligands, that is, $\left(M_{\mathrm{n}(\mathrm{SEC})}\right.$ of $\mathrm{PS}^{\mathrm{I}}$-tapy $)+\left(M_{\mathrm{n}(\mathrm{SEC})}\right.$ of PHIC-tapy $) \times 2=11100, \quad\left(M_{\mathrm{n}(\mathrm{SEC})}\right.$ of PHIC-tapy $)+\left(M_{\mathrm{n}(\mathrm{SEC})}\right.$ of PS $^{\mathrm{I}}$-tapy $) \times 2=10200, \quad\left(M_{\mathrm{n}(\mathrm{SEC})} \quad\right.$ of $\left.\quad \mathrm{PS}_{2}^{\mathrm{I}}{ }^{-\mathrm{tapy}}\right)+\left(M_{\mathrm{n}(\mathrm{SEC})} \quad\right.$ of 
Table 3 Synthesis of star polymer Ru(II) complexes with three and four mikotoarms.

\begin{tabular}{|c|c|c|c|c|}
\hline Run & Polymers & Yield (\%) & $M_{n(S E C)}{ }^{a}$ & $M_{w} / M_{n}{ }^{a}$ \\
\hline 16 & $\left(\mathrm{Ru}\left(\mathrm{PS}^{\prime}-\text { tapy }\right)_{3}\right)\left(\mathrm{SbF}_{6}\right)_{2}$ & 74.0 & 8200 & 1.17 \\
\hline 17 & $\left(\mathrm{Ru}\left(\mathrm{PS} \mathrm{I}^{-}\right.\right.$tapy $\left.)(\mathrm{PHIC} \text {-tapy })_{2}\right)\left(\mathrm{SbF}_{6}\right)_{2}$ & 51.0 & 9900 & 1.13 \\
\hline 18 & $\left(\mathrm{Ru}(\mathrm{PHIC} \text {-tapy)(PS'-tapy) })_{2}\right)\left(\mathrm{SbF}_{6}\right)_{2}$ & 62.0 & 9500 & 1.11 \\
\hline 19 & $\left(\mathrm{Ru}\left(\mathrm{PS}_{2}{ }_{2} \text {-bitapy)(PSO-tapy)(DMSO))(SbF}\right)_{2}\right.$ & 76.0 & 12200 & 1.10 \\
\hline 20 & 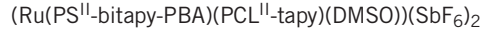 & 64.0 & 25600 & 1.12 \\
\hline 21 & $\left(\mathrm{Ru}\left(\mathrm{PS}^{\mathrm{II}} \text {-bitapy-PBA)(PSO-tapy)(DMSO))(SbF}\right)_{2}\right.$ & 82.0 & 16800 & 1.11 \\
\hline 22 & $\left(\mathrm{Ru}\left(\mathrm{PS}_{2} \mathrm{I}_{2} \text {-bitapy }\right)_{2}\right)\left(\mathrm{SbF}_{6}\right)_{2}$ & 86.0 & 14800 & 1.08 \\
\hline 23 & $\left(\mathrm{Ru}\left(\mathrm{PS}^{\mathrm{II}} \text {-bitapy-PBA) }\right)_{2}\right)\left(\mathrm{SbF}_{6}\right)_{2}$ & 45.4 & 21400 & 1.13 \\
\hline 24 & $\left(\mathrm{Ru}\left(\mathrm{PS}_{2}{ }_{2}\right.\right.$-bitapy $)\left(\mathrm{PHIC}_{2}\right.$-bitapy) $)\left(\mathrm{SbF}_{6}\right)_{2}$ & 19.2 & 11900 & 1.14 \\
\hline 25 & $\left(\mathrm{Ru}\left(\mathrm{PS}^{\prime \prime} \text {-bitapy-PBA)(PSO-bitapy-PCL'))(SbF } 6\right)_{2}\right.$ & 50.6 & 26500 & 1.11 \\
\hline
\end{tabular}

a Determined by size exclusion chromatography (SEC) in $\mathrm{CHCl}_{3}$ using polystyrenes (PS) standards.

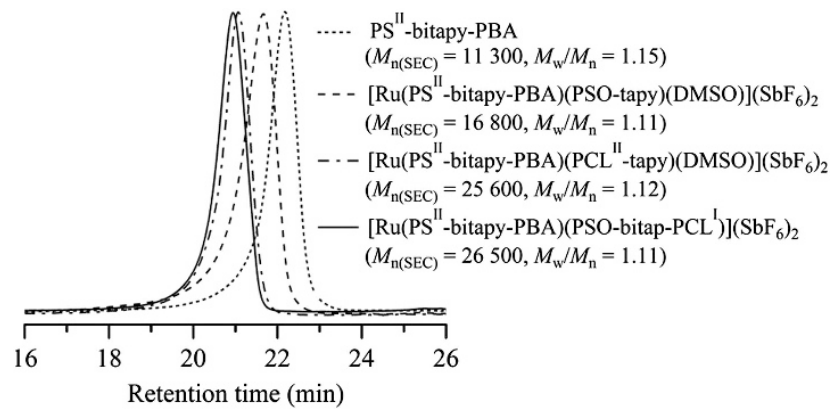

Figure 5 SEC traces of PS"l-bitapy-PBA ligand, three-miktoarm (Ru(PS"I bitapy-PBA)(PSO-tapy)(DMSO))(SbF $)_{2}$ and (Ru(PS II-bitapy-PBA)(PCL IItapy)(DMSO)) $\left(\mathrm{SbF}_{6}\right)_{2}$, and four-miktoarm (Ru(PS"I-bitapy-PBA)(PSO-bitapy$\left.\left.P C L^{\prime}\right)\right)\left(\mathrm{SbF}_{6}\right)_{2}\left(\mathrm{CHCl}_{3}\right.$ at the flow of $\left.0.8 \mathrm{ml} \cdot \mathrm{min}^{-1}\right)$.

PSO-tapy $)=10800,\left(M_{\mathrm{n}(\mathrm{SEC})}\right.$ of PS ${ }^{\mathrm{II}}$-bitapy-PBA $) \times 2=22600$ and $\left(M_{\mathrm{n}(\mathrm{SEC})}\right.$ of $\mathrm{PS}_{2}{ }_{2}$-bitapy $)+\left(M_{\mathrm{n}(\mathrm{SEC})}\right.$ of $\mathrm{PHIC}_{2}$-bitapy $)=16300$. The formation of the $\mathrm{AB}_{2^{-}},(\mathrm{AB})_{2^{-}}$and $\mathrm{A}_{2} \mathrm{~B}_{2^{-}}$-type miktoarm star copolymers $\mathrm{Ru}(\mathrm{II})$ complexes were also confirmed by the SEC measurements and ${ }^{1} \mathrm{H}$ NMR spectra, as shown in Supplementary Figures $\mathrm{S} 13$ and $17-18$.

\section{CONCLUSION}

The miktoarm copolymer $\mathrm{Ru}(\mathrm{II})$ complexes, $\mathrm{AB}_{2}$-type of $\left(\mathrm{Ru}\left(\mathrm{PS}^{\mathrm{I}}\right.\right.$ tapy)(PHIC-tapy $\left.)_{2}\right)\left(\mathrm{SbF}_{6}\right)_{2},\left(\mathrm{Ru}\left(\mathrm{PS}^{\mathrm{I}} \text {-tapy }\right)_{2}(\mathrm{PHIC}-\right.$ tapy $\left.)\right)\left(\mathrm{SbF}_{6}\right)_{2}$ and $\left(\mathrm{Ru}\left(\mathrm{PS}_{2} \mathrm{I}_{\text {-bitapy }}\right)(\mathrm{PSO}\right.$-tapy)(DMSO) $)\left(\mathrm{SbF}_{6}\right)_{2} ; \mathrm{ABC}$-type of $\left(\mathrm{Ru}\left(\mathrm{PS}^{\mathrm{II}}\right.\right.$ bitapy-PBA)(PSO-tapy)(DMSO) $\left.\left(\mathrm{SbF}_{6}\right)_{2}\right)$ and $\left(\mathrm{Ru}\left(\mathrm{PS}^{\mathrm{II}}\right.\right.$-bitapy$\mathrm{PBA})\left(\mathrm{PCL}^{\mathrm{II}}\right.$-tapy) $\left.(\mathrm{DMSO})\right)\left(\mathrm{SbF}_{6}\right)_{2}$; $(\mathrm{AB})_{2}$-type of (Ru(PSII-bitapy$\left.\mathrm{PBA})_{2}\right)\left(\mathrm{SbF}_{6}\right)_{2} ; \quad \mathrm{A}_{2} \mathrm{~B}_{2}$-type of $\left(\mathrm{Ru}\left(\mathrm{PS}_{2}{ }_{2}\right.\right.$-bitapy $)\left(\mathrm{PHIC}_{2}\right.$-bitapy) $\left(\mathrm{SbF}_{6}\right)_{2}$; and $\mathrm{ABCD}$-type of (Ru(PS ${ }^{\mathrm{II}}$-bitapy-PBA)(PSO-bitapy$\left.\left.\mathrm{PCL}^{\mathrm{I}}\right)\right)\left(\mathrm{SbF}_{6}\right)_{2}$, were readily synthesized by the stepwise chelating interaction between the polymer-substituted tapy and bitapy ligands, which were prepared by the combination of the controlled/living polymerizations and click reaction, and $\mathrm{Ru}(\mathrm{II})(\mathrm{DMSO})_{4} \mathrm{Cl}_{2}$. The application of $\mathrm{Ru}(\mathrm{II})(\mathrm{DMSO})_{4} \mathrm{Cl}_{2}$ afforded a simple way to synthesize the stable polymer $\mathrm{Ru}(\mathrm{II})$ mono-complex. In addition, the polymer $\mathrm{Ru}(\mathrm{II})$ mono-complex was easily isolated and chelated with different polymer-substituted tapy and bitapy ligands to form the miktoarm copolymer $\mathrm{Ru}$ (II) complexes. To the best of our knowledge, this study is the first one to report the simple arm-first synthesis of miktoarm star copolymers by the click-to-chelate method, which
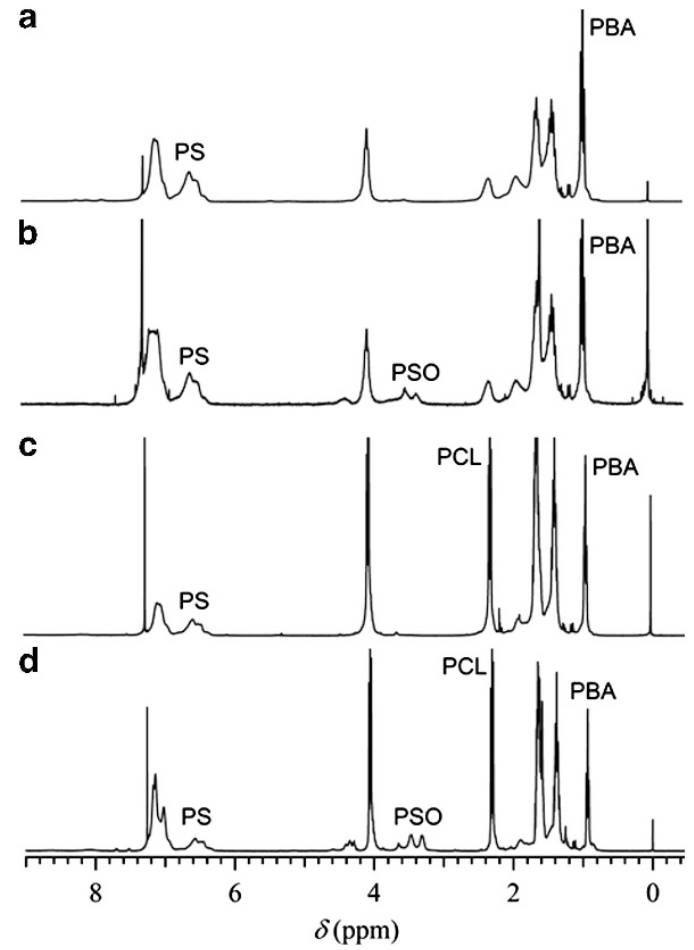

Figure $6{ }^{1}$ HNMR spectra of (a) PS"l-bitapy-PBA ligand, (b) three-miktoarm (Ru(PS II-bitapy-PBA)(PSO-tapy)(DMSO))(SbF $)_{2}$, (c) (Ru(PSII-bitapy-PBA)(PCL"Itapy)(DMSO))( $\left(\mathrm{SbF}_{6}\right)_{2}$ and (d) four-miktoarm (Ru(PS"l-bitapy-PBA)(PSO-bitapy$\mathrm{PCL}))\left(\mathrm{SbF}_{6}\right)_{2}$ determined in $\mathrm{CHCl}_{3}$.

involves a non-covalent connection between $\mathrm{Ru}(\mathrm{II})$ and the arm polymer ligands. This method provides a method for the preparation of the miktoarm star copolymers. The further designs of polymer architectures by the click-to-chelate method are currently under investigation.

\section{ACKNOWLEDGEMENTS}

This study was partially supported by the Global COE Program (Catalysis as the Basis for Innovation in Materials Science) from the Ministry of Education, Culture, Sports, Science and Technology. The author, Chen Y, was supported by a Grant-in-Aid from the Japan Society for the Promotion of Science (JSPS) Fellows.

1 Lamba, J. \& Fraser, C. Synthesis of metal-centered star-shaped polyoxazolines using $\mathrm{Fe}(\mathrm{II})$ and $\mathrm{Ru}(\mathrm{II})$ tris-bipyridine derivatives as multifunctional initiators. J. Am. Chem. Soc. 119, 1801-1802 (1997)

2 Collins, J. \& Fraser, C. Transition metals as templates for multifunctional initiators: bulk atom transfer radical polymerization of styrene using di-, tetra- and hexafunctional ruthenium tris(bipyridine) reagents. Macromolecules 31, 6715-6717 (1998).

3 McAlvin, J. \& Fraser, C. Polymerization of 2-ethyl-2-oxazoline using di-, tetra-, and hexafunctional ruthenium tris(bipyridine) metalloinitiators. Macromolecules $\mathbf{3 2}$ 6925-6932 (1999)

$4 \mathrm{Wu}$, X. \& Fraser, C. Architectural diversity via metal template-assisted polyme synthesis: a macroligand chelation approach to linear and star-shaped polymeric ruthenium tris(bipyridine) complexes. Macromolecules 33, 4053-4060 (2000).

5 Kelch, S. \& Rehahn, M. Synthesis and properties in solution of rodlike, 2,2':6', $2^{\prime \prime}$-terpyridine-based ruthenium(II) coordination polymers. Macromolecules 32 5818-5228 (1999).

6 Gohy, J., Chiper, M., Guillet, P., Fustin, C., Hoeppener, S., Winter, A., Hoogenboom, R. \& Schubert, U. S. Self-organization of rod-coil tri- and tetra-arm star metallosupramolecular block copolymers in selective solvents. Soft Matter 5, 2954-2961 (2009)

7 Chan, T., Hilgraf, R., Sharpless, K. \& Fokin, V. Polytriazoles as copper(I)-stabilizing ligands in catalysis. Org. Lett. 6, 2853-2855 (2004). 
8 Li, Y., Huffman, J. \& Flood, A. Can terdentate 2,6-bis(1,2,3-triazol-4-yl)pyridines form stable coordination compounds? Chem. Commun. 26, 2692-2694 (2007).

9 Fletcher, J., Bumgarner, B., Engels, N. \& Skoglund, D. Multidentate 1,2,3-triazole0containing chelators from tandem deprotection/click reactions of (trimethylsilyl)alkynes and comparison of their ruthenium(II) complexes. Organometallics 27, 5430-5433 (2008).

10 Meudtner, R., Ostermeier, M., Goddard, R., Limberg, C. \& Hecht, S. Multifunctional "clickates" as versatile extended heteroaromatic building blocks: efficient synthesis via click chemistry, conformational preferences, and metal coordination. Chem. Eur. J. 13, 9834-9840 (2007)

11 Richardson, C., Fitchett, C., Keene, F. \& Steel, P. 4,5-Di(2-pyridyl)-1,2,3-triazolate: the elusive member of a family of bridging ligands that facilitate strong metal-metal interactions. Dalton Trans. 19, 2534-2537 (2008).

12 Mattiuzzi, A., Jabin, I., Moucheron, C. \& Mesmaeker, K. Ru-tap complexes with btz and pytz ligands: novel candidates as photooxidizing agents. Dalton Trans. 40, 7395-7402 (2011).

13 Happ, B., Friebe, C., Winter, A., Hager, M. D., Hoogenboom, R. \& Schubert, U. S. 2-(1 H-1,2,3-triazol-4-yl)-pyridine ligands as alternatives to 2,2 '-bipyridines in ruthenium(II) complexes. Chem. Asian J. 4, 154-163 (2009).

14 Munuera, L. \& O'Reilly, R. K. Using metal-ligand interactions for the synthesis of metallostar polymers. Dalton Trans. 39, 388-391 (2010).

15 Zhang, C. H., Shen, X. D., Sakai, R., Gottschaldt, M., Schubert, U. S., Hirohara, S., Tanihara, M., Yano, S., Obata, M., Xiao, N., Satoh, T. \& Kakuchi, T. Syntheses of 3-Arm and 4-Arm Star-Branched Polystyrene Ru(II) Complexes by the Click-to-Chelate Approach. J. Polym. Sci. A Polym. Chem. 49, 746-753 (2011).
16 Lohmeijer, B. \& Schubert, U. S. Supramolecular engineering with macromolecules: an alternative concept for block copolymers. Angew. Chem. Int. Ed. 41, 3825-3829 (2002).

17 Joon Cho, T., Moorefield, C., Hwang, S., Wang, P., Godínez, L., Bustos, E. \& Newkome, G. Formation of a series of [\{methylphenylenebis(terpyridine) $\}_{n} R^{\prime \prime}{ }_{n-1}$, $(n=2-6)$ oligomers in a single-pot reaction. Eur. J. Org. Chem. 18, 4193-4200 (2006).

18 Evans, I., Spencer, A. \& Wikinson, G. Dichlorotetrakis(dimethyl sulphoxide)rutheniu$\mathrm{m}(\mathrm{II})$ and its use as a source material for some new ruthenium(II) complexes. Chem. Soc. Dalton Trans. 204-209 (1973).

19 Smalley, S., Waterland, M. \& Telfer, S. Heteroleptic dipyrrin/bipyridine complexes of ruthenium(II). Inorg. Chem. 48, 13-15 (2009).

20 Speers, A. E., Adam, G. C. \& Cravatt, B. F. Activity-based protein profiling in vivo using a copper(I)-catalyzed azide-alkyne $3+2$ cycloaddition. J. Am. Chem. Soc. 125, 4686-4687 (2003).

21 Orita, A., Nakano, T., An, D. L., Tanikawa, K., Wakamatsu, K. \& Otera, J. Metal-assisted assembly of pyridine-containing arylene ethynylene strands to enantiopure double helicates. J. Am. Chem. Soc. 126, 10389-10396 (2004).

22 Makiguchi, K., Satoh, T. \& Kakuchi, T. Diphenyl phosphate as an efficient cationic organocatalyst for controlled/living ring-opening polymerization of $\delta$-valerolactone and $\varepsilon$-caprolactone. Macromolecules 44, 1999-2005 (2011).

23 Misaka, H., Sakai, R., Satoh, T. \& Kakuchi, T. Synthesis of high molecular weight and end-functionalized poly(styrene oxide) by living ring-opening polymerization of styrene oxide using the alcohol/phosphazene base initiating system. Macromolecules 44, 9099-9107 (2011).

Supplementary Information accompanies the paper on Polymer Journal website (http://www.nature.com/pj) 